ISSN 0103-9954

\title{
O SUB-BOSQUE DE REFLORESTAMENTOS DE PINUS EM SÍTIOS DEGRADADOS DA REGIÃO DA FLORESTA ESTACIONAL DECIDUAL DO RIO GRANDE DO SUL ${ }^{1}$
}

\author{
UNDERSTOREY OF PINE-PLANTATIONS ON DEGRADED SITES IN THE REGION OF \\ DECIDUOUS FORESTS OF RIO GRANDE DO SUL
}

\author{
Franz H. Andrae ${ }^{2}$ Renato Palumbo ${ }^{3}$ José Newton Cardoso Marchiori $^{4}$ Miguel Antão Durlo ${ }^{5}$
}

\section{RESUMO}

Analisou-se o sub-bosque de 12 povoamentos de Pinus sp. e um de Araucaria angustifolia O.Ktze., crescendo em solos degradados pelo uso agrícola na chamada $4^{\text {a }}$ Colônia do Rio Grande do Sul. A Araucaria foi semeada diretamente, um dos povoamentos de Pinus, de 10 anos, resultou de uma renovação natural, os demais provêm de plantios de 25 a 30 anos atrás. Em 575 parcelas de $25 \mathrm{~m}^{2}$ cada, distribuídas sistematicamente nos povoamentos, foram levantados o estrato arbóreo e a vegetação inferior, classificada em estratos de 0,3 a $1,3 \mathrm{~m}$ e maior que $1,3 \mathrm{~m}$; no estrato inferior a $0,3 \mathrm{~m}$ somente a renovação natural de Pinus foi contada. A vegetação interna dos povoamentos se compôs de 121 espécies lenhosas, incluindo espécies desde comuns até nobres, mas também ornamentais ou frutíferas nativas e exóticas. Um bom número de espécies, porém, ocorreu com poucos representantes. Além disso registrou-se a presença freqüente de espécies não-arbóreas como ervas, gramas, samambaias e cipós. O número de espécies e o grau de cobertura do sub-bosque não dependiam da densidade do estrato superior de pinheiros. A abundância e a freqüência das espécies não variavam significativamente entre parcelas do centro dos povoamentos e da faixa periférica. O padrão de distribuição espacial das plantas dentro dos povoamentos foi quantificado pelo Índice de Cox. O Índice de Shannon foi usado como medida da diversidade em espécies; pelo Índice de Sörensen foi estudada a semelhança dos povoamentos. Conclui-se que plantios de exóticas nessa região não somente podem ser de interesse para os agricultores pelo elevado potencial produtivo em madeira, como também significam manchas de inesperada biodiversidade numa paisagem degradada. A riqueza do sub-bosque possivelmente se deve á extensão reduzida desses povoamentos.

Palavras-Chave: Pinus elliottii; Pinus taeda; Araucaria angustifólia; diversidade.

\section{ABSTRACT}

In the central part of Rio Grande do Sul State understoreys of 12 stands of Pinus sp. and one of Araucaria angustifolia O.Ktze were studied, all growing on soils, degraded by agriculture. One pine stand, 10 years old, originated from a natural renovation, the others had been planted 25 to 30 years ago, Araucaria was seeded directly. A total of 575 plots were sampled, $25 \mathrm{~m}^{2}$ each, distributed systematically within the stands. Measurements included pines overstorey, and all understorey woody species, separeted into layers of more than $1,3 \mathrm{~m}$ high and 1,3 to $0,3 \mathrm{~m}$; the layer lower than $0,3 \mathrm{~m}$ included only natural renovation of pines. Understoreys were composed by 121 species, ocurring common and high value timber species, ornamental trees, native and exotic fruit tree species. A higher number of species was present with a very few individuals only. The presence of non woody species like grasses, herbs, ferns and lians also was quantified. The number of tree species and the presence of non woody species did not correlat with density of overstorey pines. Abundance and frequency of species showed no significant diferences, when samples were grouped according to their location in the center or close to stands edge. Distribution pattern of understorey trees within stands was quantified, using Cox' index, species diversity was compared by means of Shannon-index. Similarity of stands was compared by Sörensen-Index. It was concluded, that exotic species planted on poor

1. Trabalho dedicado ao Ex-Prefeito do município de Faxinal do Soturno, Sr. Eusébio R. Busanello. Os reflorestamentos em propriedades coloniais por ele incentivados já nos anos 70, possibilitaram este estudo.

2. Engenheiro Florestal, Dr., Department Wald und Bodenwissenschaften, Universität für Bodenkultur, A-1190 Viena, Áustria. franz.andrae@boku.ac.at

3. Engenheiro Florestal, Department Wald und Bodenwissenschaften, Universität für Bodenkultur, A-1190 Viena, Áustria.

4. Engenheiro Florestal, Dr., Professor Titular do Departamento de Ciências Florestais, Centro de Ciências Rurais, Universidade Federal de Santa Maria, CEP 97105-900 Santa Maria (RS).

5. Engenheiro Florestal, Dr., Professor Adjunto do Departamento de Ciências Florestais, Centro de Ciências Rurais, Universidade Federal de Santa Maria, CEP 97105-900 Santa Maria (RS).migueldurlo@smail.ufsm.br

Recebido para publicação em 16/03/2004 e aceito em 23/08/2004. 
agricultural soil may not only be of farmers interest because of their high potential for wood production. These plantations also may be considered from conservationist point of view, since they show an unexpected high diversity, so contributing in a longer run to landscape improvement, possibly due to the small extension of stands.

Key-words: Pinus elliottii; Pinus taeda; Araucaria angustifolia; diversity.

\section{INTRODUÇÃO}

A colonização agrícola do Rio Grande do Sul, iniciada na primeira metade do século IXX, aos poucos, alastrou-se sobre todas as regiões originalmente florestadas. A abertura da região do presente estudo, parte da chamada $4^{\text {a }}$ Colônia de Imigração Italiana, deu-se a partir de 1880 (Jannasch, 1898; Bellinaso, 2000). Desbravaram-se as matas desconsiderando futuras necessidades de disponibilidade de madeira ou de funções ecológicas florestais: alertas (Zell, 1929) ou atividades pró-floresta (Minssen, 2001) foram ultrapassadas pela dinâmica e política do desenvolvimento agrícola. Foi, nos anos 60, que finalmente começou a época dos reflorestamentos, criando-se quase que exclusivamente maciços industriais, enquanto nas colônias raramente surgiram povoamentos - só de pequena extensão e destinados ao consumo no próprio minifúndio. Na paisagem gaúcha de exuberante variabilidade subtropical, esses plantios se destacam por uma grande uniformidade de estrutura e composição. $O$ interesse até então se restringiu, sobretudo, a sua produtividade volumétrica.

Este trabalho analisa alguns desses pequenos povoamentos e tem por finalidade o conhecimento da produtividade local, e da situação do sub-bosque, quanto à sua composição florística e padrões de distribuição, com objetivo de pensar em opções de manejo futuro.

\section{REVISÃO BIBLIOGRÁFICA}

Faz pouco tempo, que os sub-bosques de monoculturas estabelecidas em ambientes tropicais e subtropicais começaram a ser estudados, e chamou atenção a sua riqueza em espécies. Uma rede global de estudos sobre esse assunto foi criada (Parrota et al., 1997), e pensou-se na possibilidade de utilizar tais plantações, de Pinus sp. por exemplo, para reestabelecer a diversidade da vegetação original (Lugo, 1997; Haggar et al., 1997; Harrington et al., 1997; Geldenhuys, 1997) ou para iniciar um melhoramento de sítios degradados (Guaariguata et al., 1995). Outras publicações (Loumette et al., 1997; Bone et al., 1997; Fang et al., 1997; Keenan et al., 1997; Hummel, 2000; Yirdaw, 2001, Brockerhoff et al., 2003) também se referem à diversidade apreciável do sub-bosque de plantações de exóticas. Saha (1997) e Oberhauser (1997) encontraram, nos sub-bosques de plantações de teca e de Pinus sp. respectivamente, maior diversidade do que nas capoeiras adjacentes, enquanto Healey e Gara (2003), comparando capoeira e sub-bosque de teca, acharam uma maior diversidade nas capoeiras.

Os trabalhos acima citados foram realizados na Ásia, África ou na América Central, faltando referência na literatura internacional a estudos correspondentes em plantações de exóticas na América do Sul.

Nos estudos mencionados, os métodos usados para os levantamentos de campo variavam bastante, e as análises dos dados em geral incluíram a relação de espécies e o cálculo de alguns indicadores de diversidade. Magurran (1988) descreve e exemplifica um bom número de tais índices, dos quais a literatura atual se serve para avaliar a complexidade das estruturas horizontais e verticais de vegetação mista. $\mathrm{O}$ lançamento do termo biodiversidade na convenção Rio 92, aliás, foi o ponto de partida para a difusão quase que repentina (Duelli e Obrist, 2003) dessas medidas, para quantificar o modo de composição de fauna ou flora de ecossistemas. Para calcular índices de diversidade de estratos arbóreos de florestas, também podem ser empregados parâmetros dendrométricos como diâmetros, alturas e medidas de copa; já para caracterizar a vegetação inferior, os índices necessariamente podem ser calculados apenas a partir de dados de freqüências. Os índices de muitos estudos publicados, infelizmente, possuem comparabilidade limitada quando os levantamentos não se baseiam em amostras de tamanhos idênticos (Eckmüllner, 1998; Stockwell and Peterson, 2002).

No Sul do Brasil, Ivanauskas et al. (1999), Longhi et al. (2000) e Nascimento et al. (2001), empregaram tais índices para caracterizar tipos de florestas nativas, e Nappo et al. (2001) quantificaram a estrutura do sub-bosque de um povoamento de bracatinga. No Brasil Central, Scheuber (1998) usou 
indicadores para comparar tipos de florestas e Leite (2001), para quantificar a forma de distribuição de espécies numa floresta de galeria. Nebel et al. (2001 a, 2001 b) caracterizaram mediante tais indicadores sítios e estratos arbóreos da floresta equatorial do Peru.

\section{MATERIAL E MÉTODOS}

Nos municípios de Faxinal do Soturno e de São João do Polêsine, situados na transição entre a Depressão Central e a Encosta Sul do Planalto Riograndese, existem pequenos reflorestamentos, implantados no início dos anos $70 \mathrm{em}$ solos então pouco produtivos para fins agrícolas. Hoje os povoamentos estão cercados de capoeiras, lavouras ou pastagens. No verão de 1999, foram analisados 11 povoamentos de Pinus $s p$. de 25 a 30 anos, plantados em espaçamento de 2 por $2 \mathrm{~m}$, hoje com 600 a 1.600 árvores por hectare e um povoamento de Pinus sp., de 10 anos, que se origina de uma renovação natural, agora com 2.300 árvores/ha. O décimo terceiro povoamento era de Araucaria angustifolia, com setecentas árvores/ha, que foi implantado mediante semeadura direta 28 anos antes das medições.

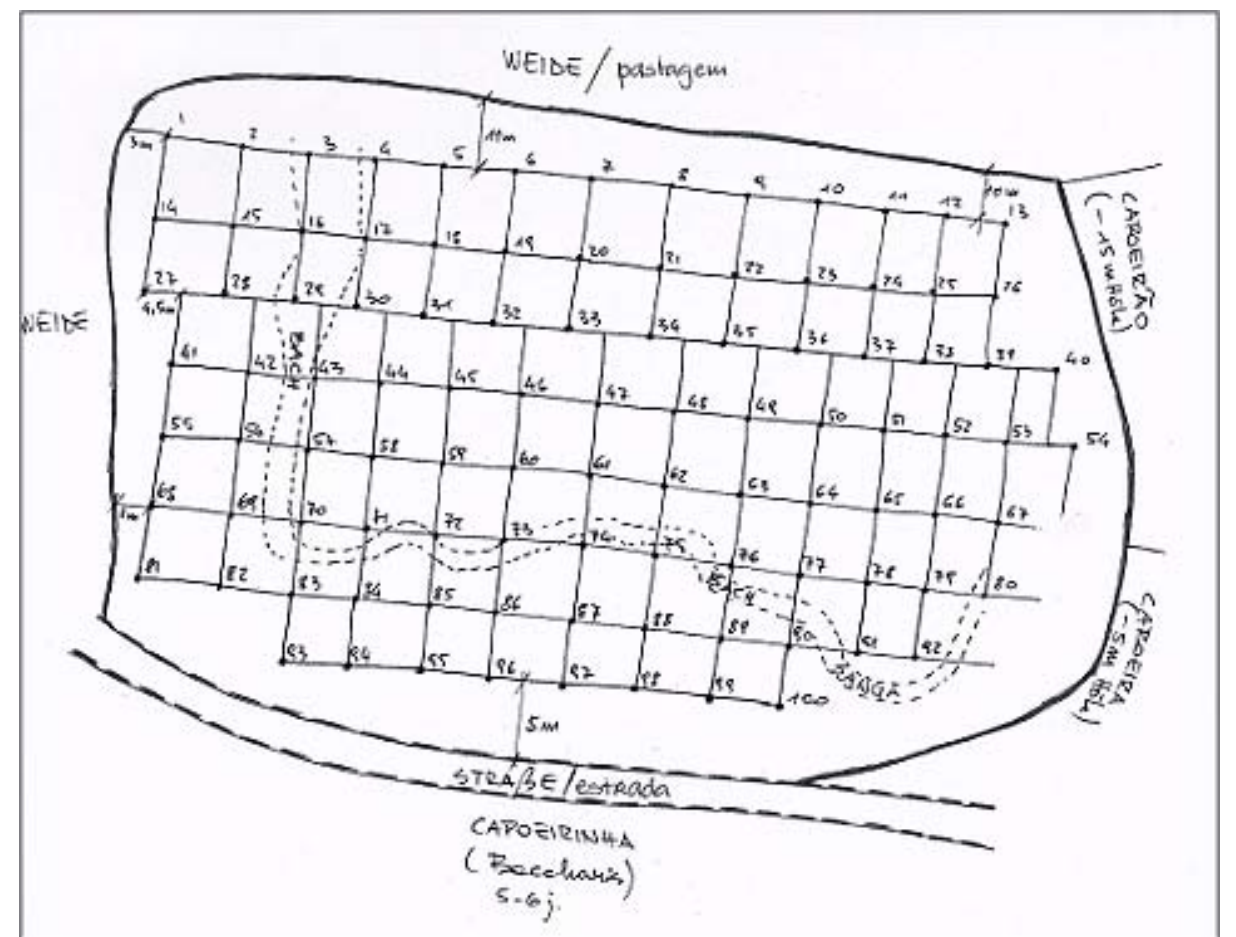

FIGURA 1: Esquema de localização das amostras no povoamento n. 6. Os pontos enumerados assinalam os centros de amostras de $25 \mathrm{~m}^{2}$ cada.

FIGURE 1: Scheme of localization of samples within stand 6. Numbered points are the centers of samples of $25 \mathrm{~m}^{2}$ each.

Do total de 13 povoamentos, 11 se encontram numa região de 6 por $8 \mathrm{~km}$, os dois restantes ficam numa distância de cerca de $10 \mathrm{~km}$. Os povoamentos 1 e 3 são vizinhos, o que também vale para os de número 4 e 5, os demais ficavam numa distância mínima de $100 \mathrm{~m}$ um do outro. As áreas dos povoamentos variavam de 0,2 a 1,0 ha. Nestes, localizaram-se amostras circulares de $25 \mathrm{~m}^{2}$, num espaçamento quadrático de $10 \mathrm{~m}$, como se vê no esquema na Figura 1 (Palumbo,1999). Com esse método de amostragem abrangeram-se $25 \%$ da área de todos os povoamentos.

Em cada parcela, além de levantar características do sítio (topografia, etc.), foram medidos diâmetros, alturas e outros parâmetros dendrométricos dos pinheiros vivos e mortos (estrato $\mathrm{A}=$ estrato superior). Numa subamostra, determinou-se o volume do tronco pelo método de Hohenadl para calcular fatores de forma local. As medições de diâmetros ao longo do tronco de 67 exemplares de Pinus sp. e de cinco de pinheiro brasileiro foram feitos com o auxílio de um telerelascópio de Bitterlich.

Em cada parcela, foram identificados e contados os indivíduos das espécies lenhosas do estrato 
inferior, dividido nas camadas de 0,3 a 1,3 m (estrato C) e maior que 1,3 m (estrato B); também foi estimado o grau de cobertura das plantas não lenhosas, divididas em gramas, ervas, samambaias e cipós.

Numa área de $1 \mathrm{~m}^{2}$, localizada no centro de cada parcela, contou-se o número de pinheiros inferiores a $30 \mathrm{~cm}$ (estrato D), mediu-se a espessura da liteira.

Levantaram-se 575 amostras, vinte das quais localizadas no povoamento de pinheiros-brasileiros, as restantes sob Pinus.

A análise dos dados obtidos teve os seguintes objetivos: (a) verificar a potencialidade de produção dos povoamentos (b); conhecer as espécies existentes no sub-bosque e verificar a sua composição segundo características qualitativas (c); avaliar a ocorrência de plantas não-lenhosas no sub-bosque (d); calcular indicadores fitossociológicos (Cox, Shannon, Sörensen) para descrever as freqüências relativas das espécies (e); a sua diversidade; (f) e o padrão de distribuição horizontal de grupos das espécies dentro de cada povoamento e (g) para comparar os povoamentos quanto a semelhança da composição dos seus estratos inferiores.

\section{RESULTADOS E DISCUSSÃO}

\section{A produção volumétrica do estrato superior}

O volume considerado era o do tronco total. A sua determinação seguiu o procedimento clássico: estimando em cada povoamento as alturas (h) em função do diâmetro em 1,3 m (dap), usando, para tal, a relação hipsométrica do tipo: $\mathrm{h}=\exp \left(\mathrm{a}_{0}+\mathrm{a}_{1} / \mathrm{dap}\right)+1,3$. Os volumes do estoque vivo foram calculados com uma função de forma para os Pinus sp. e outra para a Araucaria, sendo as variáveis independentes testadas, valores de transformações de dap e $\mathrm{h}$, como $1 /$ dap, 1/dap 2 , 1/h e 1/(daph). Os fatores de forma médios, para os Pinus sp. eram de 0,47 e para a Araucaria de 0,56.

Nenhum dos povoamentos havia sido desbastado. A produção total, somando volume vivo e morto, foi calculada por meio da reconstrução do estoque morto, composto de árvores mortas, ainda em pé ou caídas. Considerando a falta de tratamentos e que a maioria dos povoamentos foi implantado em sítios degradados, constatou-se um desenvolvimento mais que satisfatório.

Foram encontrados estoques vivos entre 580 a $1.240 \mathrm{~m}^{3} / \mathrm{ha}$ para os Pinus de 25 a 30 anos de idade, e cerca de $280 \mathrm{~m}^{3} /$ ha para a renovação natural de 10 anos. Os incrementos volumétricos médios totais, incluindo o estoque morto, variavam para os 12 povoamentos de Pinus $s p$. entre 26 e $50 \mathrm{~m}^{3}$ por ha por ano, sendo a média e o desvio padrão do incremento $34 \pm 7 \mathrm{~m}^{3} / \mathrm{ha} / \mathrm{ano}$. A cota do estoque morto na produtividade por povoamento era de 6 a 24\%. Como a maioria dos povoamentos tinha uma idade acima de 25 anos, é bem possível que árvores mortas e caídas, há mais tempo, já não foram mais encontradas; em conseqüência disso, supomos que a produtividade média total na realidade seja ainda um pouco maior.

O povoamento de Araucaria, crescendo a $150 \mathrm{~m}$ de altitude, poderia ser considerado, "exótico", já que existe num sítio originalmente coberto pela floresta caducifólia. O estabelecimento do povoamento sofreu durante os primeiros anos por causa de danos de insolação e seca. Mesmo assim, ele se apresenta, aos 28 anos, com um estoque vivo de $398 \mathrm{~m}^{3} / \mathrm{ha}$ e um incremento médio superior a $14 \mathrm{~m}^{3} / \mathrm{ha} / \mathrm{ano}$. Não existiam ainda árvores mortas, e desconsideraram-se, neste cálculo, o volume e o incremento de algumas latifoliadas existentes junto aos pinheiros-brasileiros.

\section{A composição florística das espécies lenhosas do sub-bosque}

Nos estratos B e C, encontrou-se um total 121 espécies lenhosas, pertencentes a 41 famílias. A família das Myrtaceae era a mais representada (13 espécies), seguida por Lauraceae, Mimosaceae, Rubiaceae, Euphorbiaceae, Meliaceae e Moraceae com oito a cinco espécies cada (Tabela 1). Um indivíduo ficou sem ser identificado, Pinus taeda e Pinus elliottii foram contados como uma espécie só. Chamou atenção o grande número (11) de espécies frutíferas domésticas, além de espécies frutíferas silvestres, como ariticum, ingá-feijão, araçá, cerejeira-do-mato, guabijú, guavirova, pitangueira, sete-capotes. O número de espécies não-autóctones era apreciável, entre estas todas, as espécies ruderais - frutíferas domésticas e espécies ornamentais, cujas matrizes freqüentemente se acham no ambiente colonial. Entre as espécies identificadas nos sub-bosques, 96 podem ser consideradas como realmente autóctonas. 
TABELA 1: Número de espécies encontradas por família.

TABLE 1: Number of species found by family.

\begin{tabular}{cl}
\hline Número de espécies & \multicolumn{1}{c}{ Famílias } \\
\hline 13 & Myrtaceae \\
8 & Lauraceae \\
7 & Mimosaceae, Rubiaceae \\
5 & Rutaceae \\
4 & Euphorbiaceae, Meliaceae, Moraceae \\
3 & Bignoniaceae, Fabaceae, Flacourtiaceae, Rosaceae, Sapindaceae, Solanaceae \\
2 & Anacardiaceae, Boraginaceae, Caesalpinaceae, Sapotaceae \\
& Ebenaceae, Icacinaceae, Myrsinaceae, Ulmaceae, Verbenaceae \\
1 & Annonaceae, Aquifoliaceae, Araliaceae, Araucariaceae, Arecacea, Asteraceae, \\
& Bombacaceae, Celastraceae, Erythroxylaceae, Loganiaceae, Phytolaccaceae, \\
& Pinaceae, Polygonaceae, Rhamnaceae, Simaroubaceae, Thymelaeaceae, \\
\hline
\end{tabular}

Dividindo as espécies segundo critérios de utilidade, classificaram-se 22 como "espécies de valor" (entre estes o pinheiro brasileiro, Pinus e eucalipto), outras 16 são "espécies úteis", restando 83 como "demais espécies". Uma relação das espécies identificadas se encontra na Tabela 2.

TABELA 2: Espécies lenhosas encontradas no sub-bosque dos 13 povoamentos de coníferas estudados. TABLE 2: Woody species found at the sub-forest of the 13 settlements of conifers studied.

\begin{tabular}{|c|c|c|c|c|c|}
\hline Espécie & Família & Nome Comum & Uso & OBS & $N_{\text {pov. }}$ \\
\hline Lithraea molleoides Marchand & Anacardiac. & Aroeira-brava & 2 & & 1 \\
\hline Schinus terebinthifolius Raddi & Anacardiac. & Aroeira-vermelha & 3 & & 2 \\
\hline Mangifera indica $\mathrm{L}$. & Anacardiac. & Mangueira & 3 & $\mathrm{~F}$ & 1 \\
\hline Rollinia salicifolia Schltdl. & Annonaceae & Ariticum & 3 & & 10 \\
\hline Ilex brevicuspis Reissek & Aquifoliaceae & Caúna-da-serra & 3 & & 1 \\
\hline Schefflera morototonii (Aubl.) Maguire et al. & Araliaceae & Caixeta & 1 & & 1 \\
\hline Araucaria angustifolia (Bertol.) Kuntze & Araucariac. & Pinheiro-brasileiro & 1 & nn & 6 \\
\hline Syagrus romanzoffiana (Cham.) Glassman & Arecaceae & Coqueiro & 3 & & 10 \\
\hline Dasyphyllum spinescens (Less.) Cabrera & Asteraceae & Açucará & 3 & & 3 \\
\hline Jacaranda micrantha Cham. & Bignoniaceae & Caroba & 1 & & 4 \\
\hline Tecoma stans (L.) Kunth. & Bignoniaceae & Caroba-amarela & 3 & & 11 \\
\hline Tabebuia chrysotricha (Mart. ex DC.) Standl. & Bignoniaceae & Ipê-amarelo & 1 & $\mathrm{nn}$ & 1 \\
\hline Tabebuia heptaphylla (Vell.) Toledo & Bignoniaceae & Ipê-roxo & 1 & & 1 \\
\hline Chorisia speciosa A.St.-Hil. & Bombacaceae & Paineira & 3 & $\mathrm{nn}$ & 1 \\
\hline Cordia ecalyculata Vell. & Boraginaceae & Louro-mole & 3 & & 3 \\
\hline Patagonula americana $\mathrm{L}$. & Boraginaceae & Guajuvira & 1 & & 7 \\
\hline Cordia trichotoma (Vell.) Arráb. ex Steud. & Boraginaceae & Louro-pardo & 1 & & 3 \\
\hline Peltophorum dubium (Spreng.) Taub. & Caesalpinac. & Canafístula & 1 & $\mathrm{nn}$ & 1 \\
\hline Senna multijuga (L.C. Rich.) Irwin et Barn. & Caesalpinac. & Chuva-de-ouro & 3 & nn & 2 \\
\hline Schizolobium parahyba (Vell.) Blake & Caesalpinac. & Guapuruvú & 2 & & 1 \\
\hline Maytenus aquifolium Mart. & Celastraceae & Cancorosa & 3 & & 2 \\
\hline Diospyros kaki L. & Ebenaceae & Caquizeiro & 3 & $\mathrm{~F}$ & 2 \\
\hline Diospyros inconstans Jacq. & Ebenaceae & Maria preta & 2 & & 2 \\
\hline Erythroxylum deciduum A.St.-Hil. & Erythroxylac. & Cocão & 3 & & 9 \\
\hline Sebastiania brasiliensis Spreng. & Euphorbiac. & Branquilho-leiteiro & 3 & & 3 \\
\hline
\end{tabular}


TABELA 2: Continuação ...

TABLE 2: Continued ...

\begin{tabular}{|c|c|c|c|c|c|}
\hline Espécie & Família & Nome Comum & Uso & OBS & $N_{\text {pov. }}$ \\
\hline $\begin{array}{l}\text { Sebastiania commersoniana (Baill.) L.B.Sm. et } \\
\text { Dowas }\end{array}$ & Euphorbiac. & Branquilho & 2 & & 7 \\
\hline Gymnanthes concolor Spreng. & Euphorbiac. & Laranjeira-do-mato & 3 & & 3 \\
\hline Sapium glandulatum (Vell.) Pax. & Euphorbiac. & Pau-leiteiro & 3 & & 1 \\
\hline Alchornea triplinervia (Spreng.) Müll. Arg. & Euphorbiac. & Tanheiro & 2 & & 10 \\
\hline Myrocarpus frondosus M. Allemão & Fabaceae & Cabriúva & 1 & & 7 \\
\hline Machaerium paraguariense Hassl. & Fabaceae & Canela-do-brejo & 2 & & 12 \\
\hline Lonchocarpus campestris Mart. ex Benth. & Fabaceae & Farinha-seca & 2 & & 8 \\
\hline Dalbergia frutescens (Vell.) Britton & Fabaceae & Rabo-de-bugio & 2 & & 11 \\
\hline Banara parviflora (A. Gray) Benth. & Flacourtiac. & Cabroé-mirim & 3 & & 6 \\
\hline Banara tomentosa Clos & Flacourtiac. & Cabroé-mirim & 3 & & 4 \\
\hline Casearia sylvestris $\mathrm{Sw}$. & Flacourtiac. & Carvalhinho & 3 & & 12 \\
\hline Xylosma tweedianum (Clos.) Eichler & Flacourtiac. & Sucará & 3 & & 1 \\
\hline Citronella paniculata (Mart.) Howard & Icacinaceae & Gongonha & 3 & & 1 \\
\hline Citronella gongonha (Mart.) Howard & Icacinaceae & Gongonha & 3 & & 1 \\
\hline Persea americana Mill. & Lauraceae & Abacateiro & 3 & $\mathrm{~F}$ & 2 \\
\hline Aiouea saligna Meiss. & Lauraceae & Canela & 3 & & 4 \\
\hline Ocotea pulchra Vattimo & Lauraceae & Canela & 3 & & 2 \\
\hline Nectandra lanceolata Nees et Mart.ex Nees & Lauraceae & Canela-amarela & 1 & & 5 \\
\hline Ocotea puberula (A. Rich.) Nees & Lauraceae & Canela-guaicá & 3 & & 13 \\
\hline Ocotea pulchella Mart. & Lauraceae & Canela-lageana & 2 & $\mathrm{nn}^{*}$ & 1 \\
\hline Nectandra megapotamica (Spreng.) Mez & Lauraceae & Canela-preta & 2 & & 13 \\
\hline Cinnamomum zeylanicum (Breyn.) & Lauraceae & Canela-verdadeira & 3 & $\mathrm{nn}$ & 1 \\
\hline Strychnos brasiliensis (Spreng.) Mart. & Loganiaceae & Esporão-de-galo & 3 & & 7 \\
\hline Cabralea canjerana (Vell.) Mart. & Meliaceae & Cangerana & 1 & & 8 \\
\hline Trichilia elegans A.- Juss. & Meliaceae & Catiguá-de-ervilha & 3 & & 9 \\
\hline Trichilia claussenii C. -DC. & Meliaceae & Catiguá & 3 & & 5 \\
\hline Cedrela fissilis Vell. & Meliaceae & Cedro & 1 & & 7 \\
\hline Melia azedarach L. & Meliaceae & Cinamomo & 1 & $\mathrm{nn}$ & 6 \\
\hline Albizia austrobrasilica Burkart & Mimosaceae & Angico-branco & 3 & & 7 \\
\hline Albizia niopoides (Spruce ex Benth.) Burkhart & Mimosaceae & Angico-branco & 2 & & 1 \\
\hline Parapiptadenia rigida (Benth.) Brenan & Mimosaceae & Angico-vermelho & 1 & & 11 \\
\hline Inga marginata Willd. & Mimosaceae & Ingá-feijão & 3 & & 3 \\
\hline Mimosa bimucronata (DC.) Kuntze & Mimosaceae & Maricá & 3 & & 4 \\
\hline Enterolobium contortisiliquum (Vell.) Morong & Mimosaceae & Timbaúva & 1 & & 4 \\
\hline Acacia bonariensis Gill. ex Hook. et Arn. & Mimosaceae & Unha-de-gato & 3 & & 6 \\
\hline Morus alba L. & Moraceae & Amoreira-branca & 3 & $\mathrm{~F}$ & 4 \\
\hline Morus nigra $\mathrm{L}$. & Moraceae & Amoreira-preta & 3 & $\mathrm{~F}$ & 1 \\
\hline Sorocea bonplandii (Baill.) W.C.Burger et al. & Moraceae & Cincho & 3 & & 4 \\
\hline Ficus luschnathiana (Miq.) Miq. & Moraceae & Figueira-do-mato & 3 & & 2 \\
\hline Maclura tinctoria (L.) Don. ex Steud. & Moraceae & Tajuba & 1 & & 1 \\
\hline Myrsine umbellata Mart. & Myrsinaceae & Capororoca & 3 & & 8 \\
\hline Myrsine ferruginea Spreng. & Myrsinaceae & Capororoquinha & 3 & & 10 \\
\hline Myrcianthes gigantea (D.Legrand) D.Legrand & Myrtaceae & Araça & 3 & nn & 1 \\
\hline Calyptranthes concinna DC. & Myrtaceae & Guamirim-falso & 3 & $\mathrm{nn}$ & 1 \\
\hline Myrciaria tenella (DC.) O. Berg & Myrtaceae & Camboim & 3 & nn & 1 \\
\hline Eugenia involucrata DC. & Myrtaceae & Cerejeira-do-mato & 3 & & 2 \\
\hline Eucalyptus sp. & Myrtaceae & Eucalipto & 1 & nn & 1 \\
\hline Psidium guaiava $\mathrm{L}$. & Myrtaceae & Goiabeira & 3 & $\mathrm{~F}$ & 7 \\
\hline Myrcianthes pungens (O. Berg) D. Legrand & Myrtaceae & Guabijú & 3 & & 1 \\
\hline Gomidesia palustris (DC.) Kausel & Myrtaceae & Guamirim & 3 & & 2 \\
\hline Eugenia hyemalis Cambess. & Myrtaceae & Guamirim-miúdo & 3 & & 6 \\
\hline
\end{tabular}


TABELA 2: Continuação ...

TABLE 2: Continued ...

\begin{tabular}{|c|c|c|c|c|c|}
\hline Espécie & Família & Nome Comum & Uso & OBS & $N_{\text {pov. }}$ \\
\hline Campomanesia xanthocarpa O. Berg & Myrtaceae & Guavirova & 3 & & 7 \\
\hline Blepharocalyx salicifolius (Kunth) O. Berg & Myrtaceae & Murta & 2 & & 1 \\
\hline Eugenia uniflora L. & Myrtaceae & Pitangueira & 3 & & 10 \\
\hline Campomanesia guazumifolia (Cambess.) O. Berg & Myrtaceae & Sete-capotes & 3 & & 4 \\
\hline Phytolacca dioica $\mathrm{L}$. & Phytolaccac. & Umbú & 3 & & 1 \\
\hline Pinus spp. & Pinaceae & Pinheiro-americano & 1 & $\mathrm{nn}$ & 10 \\
\hline Ruprechtia laxiflora Meisn. & Polygonaceae & Marmeleiro-do-mato & 1 & & 6 \\
\hline Hovenia dulcis Thunb. & Rhamnaceae & Uva-do-Japão & 2 & nn & 2 \\
\hline Eriobotrya japonica Lindl. & Rosaceae & Ameixeira (do Jap.) & 3 & $\mathrm{~F}$ & 6 \\
\hline Quillaja brasiliensis (A.St.-Hil. et Tul.) Mart. & Rosaceae & Pau-sabão & 3 & & 2 \\
\hline Prunus persica Sieb. et Zucc. & Rosaceae & Pessegueiro-comum & 3 & $\mathrm{~F}$ & 4 \\
\hline Prunus sellowii Koehne & Rosaceae & Pessegueiro-do-mato & 1 & & 6 \\
\hline Psychotria carthagenensis Jacq. & Rubiaceae & Café-do-mato & 3 & & 6 \\
\hline Rudgea parquioides (Cham.) Müll. Arg. & Rubiaceae & Grinalda-branca & 3 & & 2 \\
\hline Randia armata (Swa.) DC. & Rubiaceae & Limoeiro-do-mato & 3 & & 5 \\
\hline Psychotria leiocarpa Cham. et Schltdl. & Rubiaceae & Grandiúva-d'anta & 3 & & 2 \\
\hline Coutarea hexandra (Jacq.) K. Schum. & Rubiaceae & Quina & 3 & $\mathrm{nn}$ & 2 \\
\hline Guettarda uruguensis Cham. et Schltdl. & Rubiaceae & Veludinho & 3 & & 2 \\
\hline Chomelia obtusa Cham. et Schltdl & Rubiaceae & Viuvinha & 3 & & 1 \\
\hline Citrus reticulata (Blanco) Chapot & Rutaceae & Bergamoteira & 3 & $\mathrm{~F}$ & 6 \\
\hline Helietta apiculata Benth. & Rutaceae & Canela-de-veado & 2 & & 1 \\
\hline Citrus sinensis (L.) Osbeck & Rutaceae & Laranjeira & 3 & $\mathrm{~F}$ & 3 \\
\hline Citrus aurantifolia (Christm.) Swingle & Rutaceae & Limeira & 3 & $\mathrm{~F}$ & 6 \\
\hline Zanthoxylum rhoifolium $\mathrm{L}$. & Rutaceae & Mamica-de-cadela & 3 & & 8 \\
\hline Zanthoxylum petiolare A.St.-Hil. et Tul. & Rutaceae & Mamica-folha- grande & 3 & & 1 \\
\hline Matayba elaeagnoides Radlk. & Sapindaceae & Camboatá-branco & 2 & & 9 \\
\hline Cupania vernalis Camb. & Sapindaceae & Cambotá-vermelho & 2 & & 12 \\
\hline Allophylus edulis (A.St.-Hil. et al.) Radlk. & Sapindaceae & Chale-chale & 3 & & 13 \\
\hline Allophylus guaraniticus (A.St.-Hil.) Radlk. & Sapindaceae & Chale-chale & 3 & & 2 \\
\hline Chrysophyllum gonocarpum (Mart. \& Eichler) Engl & Sapotaceae & Aguaí (folhas gr.) & 3 & & 8 \\
\hline Chrysophyllum marginatum (Hook. et Arn.) Radlk. & Sapotaceae & Aguaí-leiteiro & 3 & & 3 \\
\hline $\begin{array}{l}\text { Sideroxylon obtusifolium (Roem. \& Schult.) T.D. } \\
\text { Penn. }\end{array}$ & Sapotaceae & Sombra-de-touro & 3 & & 1 \\
\hline Picrasma crenata (Vell.) Engl. & Simaroubac. & Casca-amarga & 3 & & 1 \\
\hline Cestrum corymbosum Schltchl. & Solanaceae & Coerana & 3 & & 13 \\
\hline Acnistus breviflorus Sendtn. & Solanaceae & Espinho-de-pomba & 3 & & 1 \\
\hline Solanum mauritianum Scop. & Solanaceae & Fumo-bravo & 3 & & 5 \\
\hline Solanum pseudoquina A.St.-Hil. & Solanaceae & Joá & 3 & & 1 \\
\hline Daphnopsis racemosa Griseb. & Thymelaeac. & Embira & 3 & & 3 \\
\hline Luehea divaricata Mart. ex Zucc. & Tiliaceae & Açoita-cavalo & 1 & & 5 \\
\hline Trema micrantha (L.) Blume & Ulmaceae & Crandiúva & 3 & & 11 \\
\hline Celtis spinosa Spreng. & Ulmaceae & Taleira (esp.-de-galo) & 3 & & 2 \\
\hline Vitex megapotamica (Spreng.) Moldenke & Verbenaceae & Tarumã & 1 & & 5 \\
\hline Citharexylum solanaceum Cham. & Verbenaceae & Tarumã-pequeno & 3 & & 5 \\
\hline Hybanthus bigiblosus (A.St.-Hil) Hassl. & Violaceae & Poaia & 3 & & 1 \\
\hline Desconhecida & . & - & 3 & & 1 \\
\hline
\end{tabular}

Em que: USO 1 = espécie de valor, 2 = espécie de uso comum; 3 =demais espécies; OBS F = espécie frutífera, $\mathrm{nn}=$ espécie não-nativa na vegetação local original; $\mathrm{N}_{\text {pov. }}=$ Número entre 13 povoamentos estudados onde foi encontrada; * = espécie não-encontrada no Inventário Florestal do RS (2000/2001). 


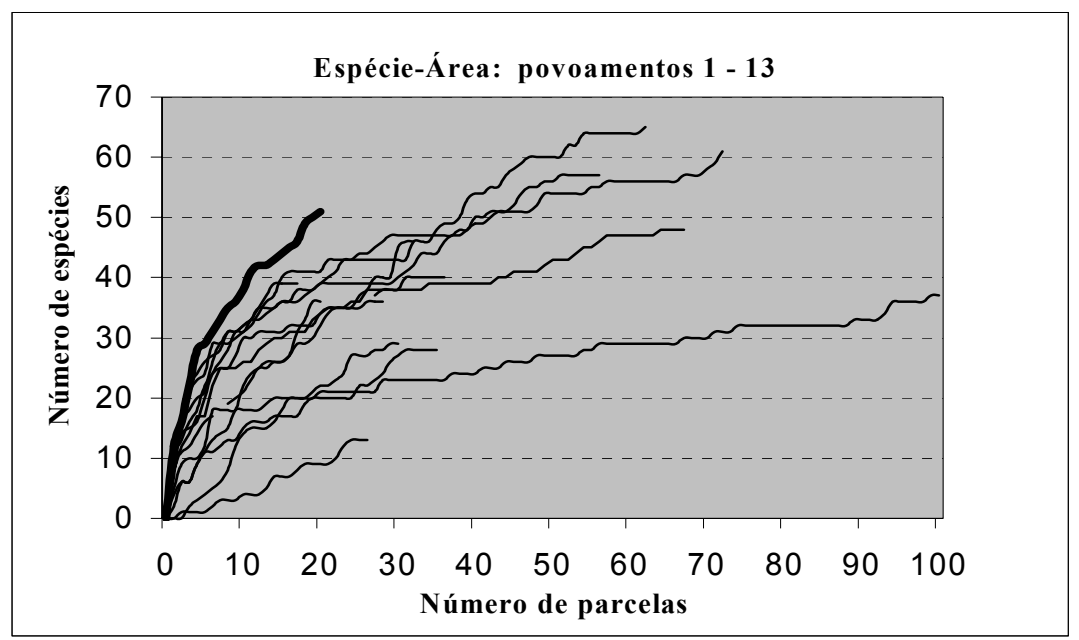

FIGURA 2: Curvas espécie-área dos povoamentos 1 a 13. A linha larga se refere à Araucaria .

FIGURE 2: Relationship between number of species and sampling effort for stands 1 to 13 . The thick line indicates the Araucaria stand.

As áreas dos povoamentos foram de extensões bem diferentes; mas isso pouco influiu na composição florística do seu estrato inferior: não foi possível comprovar uma correlação entre a área e o número de espécies.

As curvas espécie-área (Figura 2) mostram que se necessitava no mínimo vinte parcelas para abranger uma boa porcentagem das 13 a 65 espécies encontradas nos diferentes povoamentos. $\mathrm{O}$ menor número de espécies foi registrado no povoamento oriundo de renovação natural (povoamento n. 5), a freqüência máxima de espécies era do povoamento número 2, situado junto a uma área de lazer na periferia da cidade de Faxinal do Soturno e próximo de uma floresta nativa. Apesar dos níveis bem-distintos, observase, em todas as curvas espécie-área, uma tendência crescente contínua, sobretudo na Araucária. Isso indica que provavelmente existem ainda mais algumas espécies em cada povoamento, ou, considerando a intensidade e a sistemática da amostragem, que o número de espécies ainda cresça com o aumento da área do povoamento.

\section{Características quantitativas das espécies do sub-bosque}

O número de espécies que ocorrem num povoamento não informa ainda a respeito do padrão de sua distribuição e mistura. A Tabela 3 relaciona esse número total de espécies encontradas num povoamento TABELA 3: Ocorrência e distribuição de espécies do estrato inferior: no povoamento e por parcela. TABLE 3: Ocurrence and distribution of understorey-species within stands and per sample plot.

\begin{tabular}{c|rr|c}
\hline \multirow{2}{*}{ Pov. } & \multicolumn{2}{|c|}{ Número de espécies $\mathrm{n}^{\circ}$ ha } & \multirow{2}{*}{$\begin{array}{c}\text { \% parcelas sem } \\
\text { renovação }\end{array}$} \\
\cline { 2 - 3 } & Povoamento & Parcela (média, desv.padr.) & - \\
2 & 48 & $9,8 \pm 2,30$ & - \\
3 & 65 & $7,5 \pm 3,38$ & - \\
4 & 57 & $10,2 \pm 2,54$ & - \\
5 & 39 & $9,2 \pm 1,98$ & 23 \\
6 & 13 & $1,8 \pm 1,61$ & 10 \\
7 & 37 & $2,6 \pm 1,94$ & - \\
8 & 46 & $7,2 \pm 3,34$ & 1 \\
9 & 61 & $7,9 \pm 2,58$ & 6 \\
10 & 28 & $2,6 \pm 1,42$ & - \\
11 & 36 & $8,9 \pm 2,07$ & - \\
12 & 40 & $6,1 \pm 2,68$ & 7 \\
13 & 29 & $4,9 \pm 3,10$ & - \\
\hline
\end{tabular}


(coluna 2) e a média e o desvio-padrão do número de espécies encontradas por parcela de $25 \mathrm{~m}^{2}$ (colunas 3 ). Percebe-se que existem diferenças significantes entre os povoamentos. A mistura mais intensiva se observou no sub-bosque do pinheiro brasileiro, com mais de 13 espécies por parcela, enquanto nos povoamentos de Pinus, foram em média entre 2 a 10 espécies por parcela. Menos de duas espécies por parcela foram encontradas no sub-bosque do povoamento número 5.

A correlação entre o número total de espécies no povoamento e o número médio por parcela não é significativa, quer dizer, se ocorrem muitas ou poucas espécies num povoamento, não necessariamente também se encontra um número grande ou pequeno de espécies em média por parcela. Por exemplo, o povoamento 2 tem, ao total, bem mais espécies do que os povoamentos 1,10 ou 13, nos quais, porém, há um maior número de espécies por parcela, indicando uma distribuição horizontal mais uniforme.

Quanto à distribuição horizontal das plantas renovadas, nota-se que, sobretudo onde o número total de espécies foi menor, como nos povoamentos 5, 6, 9 e 12, existem manchas maiores sem renovação alguma (Tabela 3, coluna 4); no povoamento 5, que era o mais denso de todos, quase um quarto de sua área estava desprovida de renovação natural.

Todos os povoamentos se encontram cercados de lavouras, pastagens e, em especial, capoeiras. Para verificar uma eventual influência da vizinhança sobre a composição do sub-bosque, as parcelas foram classificadas de acordo com a sua localização, pertencendo mais a "periferia" ou ao "centro" do povoamento. Supõe-se que, em conseqüência as áreas dos povoamentos serem pequenas, que não foi possível comprovar (teste $\mathrm{Chi}^{2}$ ) diferenças significantes entre as parcelas da periferia e do centro, seja quanto ao número total de espécies, seja quanto à composição das espécies segundo critérios de utilidade.

Vale analisar ainda o sub-bosque quanto a sua aptidão como ponto de partida para um povoamento pós-Pinus, composto das nativas já renovadas. Dessa maneira, à geração de Pinus teria uma função acelerante para passar os estágios iniciais de capoeiras. A Tabela 4 relaciona, para os 12 povoamentos de

TABELA 4: Fração de parcelas (\%) com ocorrência das espécies relacionadas, e número médio por parcela de $25 \mathrm{~m}^{2}$. (Somente povoamentos de Pinus sp., 555 parcelas.)

TABLE 4: Percentage of sample plots with presence of mentioned species, and their mean number in plots of $25 \mathrm{~m}^{2}$. (Only pine-stands, 555 plots).

\begin{tabular}{l|c|l|c|c}
\hline Utilidade & Posição & \multicolumn{1}{c}{ Espécie } & Parcelas (\%) & $\mathrm{n}^{0}$. / $25 \mathrm{~m}^{2}$ \\
\hline \multirow{3}{*}{ Espécies de valor } & 1 & Pinus sp. & 36 & 7,7 \\
& 2 & Angico vermelho & 24 & 1,7 \\
& 3 & Tarumã & 7 & 3,8 \\
& 4 & Cedro & 7 & 1,3 \\
Espécies úteis & 5 & Canela-amarela & 5 & 1,3 \\
& 1 & Camboatá-vermelho & 45 & 3,5 \\
& 2 & Camboatá-branco & 25 & 2,7 \\
& 3 & Canela-preta & 18 & 1,7 \\
& 4 & Canela-do-brejo & 15 & 3,3 \\
& 5 & Farinha-seca & 13 & 6,4 \\
& 1 & Canela-guaicá & 48 & 2,3 \\
Demais espécies & 2 & Cestrum & 36 & 2,6 \\
& 3 & Pitangueira & 35 & 2,4 \\
& 4 & Chal-Chal & 31 & 2,2 \\
& 5 & Capororoquinha & 25 & 2,4 \\
& 6 & Coqueiro & 22 & 2,2 \\
& 7 & Carvalinho & 20 & 2,0 \\
& 8 & Capororoca & 18 & 1,8 \\
& 9 & Esporão-de-galo & 17 & 2,0 \\
& 10 & Guamirim-folha-miuda & 14 & 3,1 \\
& 11 & Cocão & 11 & 1,5 \\
& 12 & Ariticum & 10 & 1,9 \\
\hline
\end{tabular}


Pinus sp., as espécies de maior presença nos estratos acima de $30 \mathrm{~cm}$ de altura, organizadas segundo as três classes de utilidade. O grupo das "demais espécies", sem dúvida, era o mais difundido, as "espécies de valor" eram bem mais raras. Entre as espécies se destacam o camboatá-vermelho e a canela-guaicá como presentes em quase a metade das parcelas amostradas. Plantas de Pinus sp. no estrato inferior foram observadas somente em cerca de um terço das parcelas. Quando se agrupam as espécies de valor e de utilidade verificase uma situação promissora da renovação: em $88 \%$ das parcelas se observou a presença de indivíduos destes grupos.

O sub-bosque do povoamento 13, de Araucaria, era o mais rico em espécies desejáveis, pois se encontrou representantes de espécies valiosas ou úteis em cada uma das 20 parcelas, sendo as mais freqüentes: tanheiro, canjerana, canela-preta, camboatá-vermelho, canela-do-brejo, angico-vermelho.

\section{A ocorrência de espécies frutíferas domésticas, e de não-autóctonas no estrato inferior}

Em cada um dos 13 povoamentos, observaram-se algumas espécies não-autóctonas. Em $24 \%$ das parcelas foram encontradas uma ou mais espécies de frutíferas, sendo as mais freqüentes $(6,7 \%$ das parcelas) a amora, seguida da ameixa-do-japão $(5,4 \%$ das parcelas), da limeira $(4,0 \%)$ e da bergamoteira $(2,3 \%)$. A distribuição das frutíferas dentro dos povoamentos não mostrou diferenças entre parcelas de periferia ou do centro. Mas chamou atenção, que houve o máximo de incidência de frutíferas num povoamento ( $76 \%$ de suas parcelas com frutíferas) junto a uma área de lazer e num outro perto da casa de um agricultor ( $39 \%$ das parcelas).

Além das frutíferas existem ainda outras "espécies não autóctones da vegetação local", especialmente ornamentais. Sem contar a renovação de Pinus sp., foram observadas tais árvores em 12\% das parcelas, distribuídos sobre todos os povoamentos. Entre essas espécies "exóticas" os indivíduos do pinheiro brasileiro e do cinamomo foram os mais freqüentes, presentes em seis dos 13 povoamentos.

As não-autóctones, sejam frutíferas ou outras, não necessariamente devem ser consideradas invasoras, já que na sua maioria ocorrem com poucos indivíduos, além de sua fácil dispersão antropogênica.

\section{A densidade do estrato superior e o número de espécies no sub-bosque}

Foi usada a área basal das árvores de Pinus sp. e Araucaria como expressão da densidade de uma parcela para testar se esse parâmetro influi sobre o número de espécies no sub-bosque abaixo das árvores do estrato superior. Um número maior de árvores na parcela, ou árvores mais grossas, aumentam a área basal, aumentando a concorrência para o sub-bosque. Para eliminar a influência da variabilidade entre os povoamentos foi testada para cada um individualmente, se existe uma relação, assim, que pudesse ajudar a explicar o padrão de distribuição horizontal da mistura de espécies do sub-bosque. Mas, em nenhum dos povoamentos, foi verificada uma correlação significativa, indicando que a área basal não serviu para expressar um eventual efeito de densidade sobre o estrato inferior.

\section{A distribuição regional das espécies no sub-bosque}

Os povoamentos estudados situam-se mais ou menos distantes um do outro o que podia influir sobre a possível presença geral ou somente local de espécies. A coluna direita da Tabela 7 indica em quantos dos 13 povoamentos uma espécie foi encontrada.

Somente quatro espécies (canela-guaicá, cetrum, chal-chal, canela-preta) apareceram no sub-bosque de todos os povoamentos. Em 12 povoamentos, se registraram-se camboatá-vermelho, carvalinho, canela-dobrejo, em 11 povoamentos angico-vermelho, rabo-de-bugio, crandiúva, caroba-amarela. A ocorrência de outras 14 espécies foi observada em oito a dez povoamentos.

São poucas as espécies que podem então ser consideradas como onipresentes. Por outro lado, há muitas espécies raras, as quais ocorrem com pequeno número de indivíduos ou somente numa parte pequena da região abrangida pelos povoamentos em foco. De 12 espécies, por exemplo, somente foi observado um único indivíduo, sete espécies apareceram somente com dois exemplares, e seis espécies com três indivíduos. 34 , do total de 121 espécies, foram observadas somente em um dos 13 povoamentos.

A causa para a grande freqüência de certas espécies pode ser a distribuição de árvores adultas nas redondezas, a facilidade de propagação das sementes e o sub-bosque de Pinus servir como ambiente 
favorável para o seu desenvolvimento. A ocorrência das espécies raras por outro lado podia ser explicada, com a falta de árvores matrizes, com uma dificuldade de dispersão das sementes, com condições locais desfavoráveis, ou como ocorrência aleatória, quando a semente foi espalhada por pessoas na sua passagem.

São poucas as espécies nativas de maior importância econômica presentes no estrato inferior. A relação de espécies que segue observa a ordem de sua presença: canela-preta, camboatá-vermelho, canela-dobrejo, angico-vermelho, rabo-de-bugio, tanheiro, camboatá-branco, farinha-seca, canjerana, branquilho, cabreúva, cedro, guajuvira - todas essas foram encontradas em, no mínimo, metade dos povoamentos; porém, um número maior de espécies de valor ou utilidade somente foi encontrado com freqüências bem inferiores.

\section{A renovação de Pinus sp. no sub-bosque}

A renovação dos Pinus sp. mereceu atenção à parte, já que em 12 povoamentos (555 parcelas) existiam condições iguais de disponibilidade e dispersão de sementes, pois o estrato superior se compunha exclusivamente dessas mesmas espécies. Neste capítulo, foi estudada a presença de Pinus sp. no sub-bosque, com base no número de plantas contadas no estrato (B), mais alto que $1,3 \mathrm{~m}$, do estrato (C), entre 0,3 e 1,3 $\mathrm{m}$ e do estrato (D), inferior a $30 \mathrm{~cm}$. Apesar da situação vantajosa para renovação, verificou-se pinheiros novos em somente $45 \%$ das parcelas, ficando $55 \%$ sem renovação de Pinus nos 3 estratos (Tabela 5).

TABELA 5: Renovação de Pinus no sub-bosque (12 povoamentos, 555 parcelas de $25 \mathrm{~m}^{2}$ cada.). TABLE 5: Renovation of Pinus in understorey (12 stands, 555 plots of $25 \mathrm{~m}^{2}$ each).

\begin{tabular}{l|cc}
\hline \multirow{2}{*}{ Estrato } & \multicolumn{3}{|c}{ Parcelas com renovação de Pinus sp. } \\
\cline { 2 - 3 } & \% do total de parcelas & $\mathrm{n}^{\text {o }}$. de \\
\hline D: $<30 \mathrm{~cm}$ & 28 & 48.025 \\
C: $30-130 \mathrm{~cm}$ & 34 & 2.609 \\
B: $>130 \mathrm{~cm}$ & 16 & 1.477 \\
\hline B + C $+\mathrm{D}$ & 45 & 33.030 \\
\hline
\end{tabular}

Essas percentagens variam desde menos de $10 \%$ até mais de $90 \%$ das parcelas de um povoamento com presença de Pinus no sub-bosque. Mais uma vez, não se acharam diferenças significativas (teste-Chi ${ }^{2}$ ) de freqüências de renovação entre as parcelas das periferias e das partes centrais dos povoamentos.

Uma questão importante a analizar é se os Pinus existentes nos sub-bosques, seriam suficientes para compor o povoamento de uma próxima rotação. Considerando somente as parcelas com pinheiros renovados, verifica-se um bom número de indivíduos em cada um dos estratos, ou $33 \mathrm{mil} / \mathrm{ha}$, somando os três estratos $\mathrm{B}$, $\mathrm{C}$ e D. Considerando todas as parcelas, porém, fica evidente que mais da metade das parcelas estava sem renovação de pinheiros, as quais sobretudo, estavam com distribuição bem irregular dentro dos povoamentos. Quer dizer, a situação se apresentava satisfatória, somente para poucos povoamentos, onde uma grande percentagem das parcelas estava com pinheiros no sub-bosque. Na maioria dos povoamentos, porém, existiam maiores manchas desprovidas de pinheiros no estrato inferior.

Não foi possível explicar a causa da irregularidade da renovação de Pinus sp. Levantou-se a hipótese de que pudesse ser causada pela espessura da manta. Em $49 \%$ das parcelas, existia uma manta de até $5 \mathrm{~cm}$ de espessura; em $44 \%$, de 5 a $10 \mathrm{~cm}$ e em $7 \%$, acima de 10 (até 15) $\mathrm{cm}$. Comparando essas três classes de espessura de manta (teste- $\mathrm{Chi}^{2}$ ) não foi achada diferença significativa quanto à ocorrência de renovação. Selecionando somente aquelas parcelas com renovação, contou-se, em média, o seguinte número de plantas por classe de espessura: até $5 \mathrm{~cm}$ de liteira 5,0 pinheirinhos $/ \mathrm{m}^{2} ; 4,4$ pinheirinhos quando a manta média de 5 a $10 \mathrm{~cm}$ e 1,7 pinheiros em mantas mais espessas que $10 \mathrm{~cm}$. Em síntese: a falta ou presença de renovação de Pinus não se deve à espessura da manta; mas, uma vez renovado, diminui o número de plantas $/ \mathrm{m}^{2}$ quanto mais espessa a camada de liteira.

\section{Plantas não-lenhosas no sub-bosque (ervas, gramas, cipós, samambaias)}

Junto ao sub-bosque arbóreo, registram-se, em muitas parcelas, plantas do grupo das não-lenhosas. A sua presença foi quantificada estimando o "grau de cobertura" (GC), medido em \% da superfície do solo coberto. Somente $7 \%$ das 575 parcelas levantadas estavam livres de não-lenhosas, em $25 \%$ se observou a presença de um dos quatro grupos, em $45 \%$ ocorreram representantes de dois grupos, em $21 \%$ de três grupos, e em $2 \%$ das parcelas foram encontrados os 4 grupos, isto é, ervas, gramas, cipós e samambaias. 
Mais uma vez, existiam grandes diferenças entre os povoamentos, com valores do "GC" médio entre 10 e mais de $60 \%$. Pareceu que cada um dos grupos de ervas, gramas, cipós e samambaias ocorresse em média com maior freqüência nas parcelas do centro dos povoamentos do que perto da periferia; mas esta impressão não pode ser confirmada estatisticamente (teste-t), porque a amplitude dos valores de cobertura observados por parcela era muito grande. Analisando os quatro grupos separadamente (Tabela 6), reconhece-se que a contribuição dos cipós e das samambaias para o GC era menor do que a das ervas e gramíneas.

A variabilidade dos dados se deve, em boa parte à condição da luminosidade nos pinhais. $\mathrm{O}$ povoamento 5, muito denso, apresentava o mínimo (8\%) do GC registrado, valores igualmente baixos se encontraram onde houve sinais de fogo de manta. Graus de cobertura com mais de $50 \%$ se associavam geralmente a uma abertura entre as copas do estrato superior, ou, como no povoamento 2 , junto a uma área de lazer, onde o sub-bosque lenhoso freqüentemente foi roçado. Os valores de graus de cobertura mínima e máxima indicam, que o aumento da luminosidade dentro do povoamento favorece o desenvolvimento de ervas e gramas mais do que o de cipós ou samambaias (Tabela 6).

TABELA 6: Grau de cobertura (GC) de plantas não-lenhosas: dados de 12 povoamentos de Pinus sp. e de um de Araucaria.

TABLE 6: Degree of soil cover (GC) by non woody plants: data from 12 stands of Pinus sp. and one from Araucaria.

\begin{tabular}{l|c|c|c}
\hline Grupo & $\mathrm{GC}$ médio $(\%)$ & $\mathrm{GC}_{\min }(\%)$ & $\mathrm{GC}_{\max }(\%)$ \\
\hline a) ervas & 13 & 2 & 41 \\
b) gramas & 13 & 2 & 36 \\
c) cipós & 4 & 0 & 10 \\
d) samambaias & 6 & 1 & 19 \\
\hline Grupos a+b+c+d & 37 & 8 & 68 \\
\hline
\end{tabular}

O grau de cobertura de não-lenhosas e a renovação de Pinus sp., a espessura da manta e a densidade do estrato superior

Considere-se somente a situação nos 12 povoamentos de Pinus sp.: Confrontando o número de pinheiros em todo o sub-bosque analisado (estratos $\mathrm{B}+\mathrm{C}+\mathrm{D})$ e o grau de cobertura das não-lenhosas ficou claro que existiu uma correlação significante $(\mathrm{B}=0,752)$ :

$\mathrm{n}_{\text {Pinus } / \mathrm{m}^{2}}=2,22-0,0213 \cdot \mathrm{GC}_{(\%)}$

Com isso, ficou evidente que um grau de cobertura maior aumentava a concorrência, diminuindo o número de pinheiros por $\mathrm{m}^{2}$.

Conclui-se, dos dados da Tabela 7, que a espessura da camada de acículas influi sobre a densidade e a composição das não-lenhosas. Quando a manta é de pequena espessura, o GC total das não-lenhosas alcança o seu valor máximo; nessa situação, o grupo das ervas fica numa situação de dominância; mantas com mais de $5 \mathrm{~cm}$ de espessura reduzem visivelmente o grau de cobertura das ervas. No que tange às

TABELA 7: Graus de cobertura (GC) de plantas não lenhosas e classes de espessura da manta de acículas de Pinus sp.

TABLE 7: Degree of soil cover (GC) by non woody plants and thickness of needle layer in stands of Pinus $s p$.

\begin{tabular}{|c|c|c|c|}
\hline Grupo/Espessura & Manta até $5 \mathrm{~cm}$ & $5-10 \mathrm{~cm}$ & mais de $10 \mathrm{~cm}$ \\
\hline Número de parcelas & 270 & 244 & 41 \\
\hline a) ervas & 18 & 8 & 10 \\
\hline b) gramas & 15 & 14 & 5 \\
\hline c) cipós & 4 & 4 & 5 \\
\hline d) samambaias (GC\%) & 6 & 6 & 9 \\
\hline Grupos $a+b+c+d(G C \%)$ & 43 & 32 & 29 \\
\hline
\end{tabular}


gramíneas, chama atenção que o seu valor do GC continua elevado também na segunda classe de espessura da manta, diminuindo na classe de manta com mais de $10 \mathrm{~cm}$. Os cipós possuem um grau de cobertura praticamente independente da espessura da manta, e as samambaias aparentemente tendem a aumentar o seu grau de cobertura nas parcelas com manta espessa.

Também foi testado para cada povoamento, se existe uma correlação entre o grau de cobertura da vegetação não-lenhosa e a densidade do estrato superior, expressa pela área basal de Pinus por parcela. Mas não foi possível provar que existe uma dependência assim. A área basal por parcela possivelmente não é um bom indicador para correlacionar as diferenças de transparência do estrato superior dos Pinus sp. e a luminosidade perto da superfície do solo, isso porque as parcelas de $25 \mathrm{~m}^{2}$ são pequenas demais para serem sujeitas em especial à iluminação vertical sem maior influência de luz lateral.

\section{Caracterização da distribuição das espécies lenhosas do sub-bosque através de índices}

Foram usados três índices para quantificar diferentes aspectos da distribuição das espécies dentro e entre os povoamentos.

\section{O Índice de dispersão $\left(q_{x}\right)$ de COX (1971)}

O Índice de Cox informa sobre a uniformidade da distribuição espacial de plantas (estratos B + C) num povoamento (Vries, 1986). O índice de Cox é a razão variância/média, calculado no caso do presente estudo, com o número de árvores por parcela de $25 \mathrm{~m}^{2}$, agrupadas segundo classes de utilidade. As parcelas cobriam um quarto da área de cada povoamento, o que justifica a consideração do fator de correção para população finita ao calcular a variância. Nascimento et al. (2001) aplicaram esse mesmo Índice de Cox numa floresta ombrófila mista, chamando-o de Índice de Agregação de Payandeh.

Se o arranjo das plantas for ao acaso ("floresta-Poisson"), o Índice de Cox assume o valor de 1. Um índice inferior a 1 significa que a distribuição das plantas é mais uniforme e sistemática; se o índice for maior que 1, as plantas tendem a ocorrer cada vez mais em forma de grupos ou aglomerações. Exceto na „florestaPoisson", a grandeza desse índice dependerá da relação entre os tamanhos das aglomerações e a área da parcela. Por isso, o Índice de Cox não é um valor absoluto e nem sempre comparável. No caso da investigação presente, porém, é possível comparar os índices dos povoamentos, pois todas as amostras eram idênticas em forma e tamanho.

Na Tabela 8, são apresentados os índices calculados para os povoamentos, uma vez usando os dados de todas as latifoliadas, e outra vez somente das espécies de maior valor e utilidade. As plantas de Pinus sp., por serem exóticas e terem condições diferentes de proliferação, foram consideradas como um grupo aparte. Os índices definem o padrão de distribuição das plantas do sub-bosque, variando desde ao acaso até fortemente aglomerado.

TABELA 8: Índices de Cox, para latifoliadas e Pinus sp. do sub-bosque, estratos acima de $30 \mathrm{~cm}$.

TABLE 8: Cox-Index, for broadleaf species and pines of understorey higher than $30 \mathrm{~cm}$.

\begin{tabular}{c|ccc|c|c}
\hline \multirow{2}{*}{ Povoamento } & \multicolumn{2}{c}{ Í. de Cox-latifoliadas } & \multicolumn{2}{c|}{ Índice de Cox-Pinus } & Cox-latifol.+Pinus \\
\cline { 2 - 6 } & todas & de valor/util & $>30 \mathrm{~cm}$ & $<30 \mathrm{~cm}$ & $>30 \mathrm{~cm}$ \\
\hline 1 & 3,4 & 4,8 & 1,6 & 6,3 & 3,1 \\
2 & 4,0 & 3,1 & 2,4 & 2,9 & 3,7 \\
3 & 5,1 & 7,7 & 8,4 & 7,5 & 4,2 \\
4 & 0,8 & 1,6 & 4,7 & 2,8 & 1,6 \\
5 & 1,5 & 0,8 & 7,5 & 6,0 & 6,6 \\
6 & 4,1 & 4,1 & 6,7 & 13,7 & 4,2 \\
7 & 8,3 & 11,3 & 6,3 & 10,7 & 5,7 \\
8 & 2,4 & 1,6 & 2,9 & 1,0 & 2,9 \\
9 & 2,1 & 3,2 & 0,0 & 1,0 & 2,1 \\
10 & 3,1 & 5,3 & 0,0 & 0,0 & 3,1 \\
11 & 1,6 & 1,3 & 5,3 & 2,3 & 2,1 \\
12 & 5,7 & 1,9 & 33,3 & 4,1 & 21,9 \\
13 & 1,2 & 0,8 & & & \\
\hline
\end{tabular}


Considerando todas as latifoliadas juntas (Tabela 8, coluna 2), observa-se uma boa amplitude de índices, maior ainda para as latifoliadas valiosas e úteis (coluna 3). A média e o desvio-padrão do Índice de Cox dos povoamentos é de 3,5 $\pm 2,11$ para todas as latifoliadas juntas, e de 3,9 $\pm 3,08$ quando calculado para as latifoliadas de valor e de utilidade.

Os números de indivíduos por parcela (dados não-apresentados aqui) poderiam ser usados para avaliar outro aspecto da renovação no sub-bosque. Existiam em média entre 1,3 (povoamento 5) e mais de 25 (povoamentos 1 e 13) indivíduos de latifoliadas por parcela; contando somente aquelas plantas que pertencem às espécies valiosas ou úteis, os números variavam em média entre 0,4 (pov. 5) e mais de 10 (pov. 1, 3 e 13). Extrapolando os números por parcela $\left(\mathrm{de} 25 \mathrm{~m}^{2}\right)$ para um hectare, poderia-se concluir que existia um número de latifoliadas jovens suficientemente grande para garantir uma renovação quantitativamente satisfatória para formar um povoamento novo. Mas comparando os Índices de Cox, geralmente elevados, percebe-se, que essas plantas podem ter uma distribuição irregular e aglomerada, causando uma cobertura desuniforme e possivelmente incompleta da área.

Os índices de Cox e os números de plantas por parcela de $25 \mathrm{~m}^{2}$ mostravam-se correlacionados. No caso das latifoliadas valiosas e úteis a correlação era significante (ao nível de $\mathrm{p} \leq 0,042$ ), quer dizer que quanto maior o número dessas plantas, maior também a tendência de aglomeração; ou seja, para as parcelas amostradas, bastava conhecer o número médio de plantas para ter-se uma idéia da forma de sua dispersão. A Figura 3 mostra essa relação positiva.

Analisou-se separadamente a dispersão da renovação do próprio Pinus. Calculou-se o Índice de Cox para Pinus sp. no sub-bosque, para as plantas inferiores a $30 \mathrm{~cm}$ (estrato D) e para as plantas maiores de 30 $\mathrm{cm}$ (estratos $\mathrm{B}+\mathrm{C}$ ). As colunas 4 e 5 da Tabela 6 relacionam tais índices. Houveram dois povoamentos sem qualquer renovação de Pinus, sendo conseqüentemente o Índice de Cox igual a 0. A uniformidade do estrato arbóreo dos Pinus não se repetiu numa distribuição uniforme dos pinheirinhos no sub-bosque, ao contrário, os dados indicam uma tendência mais forte ainda de aglomerar-se. No povoamento 12, por exemplo, foram encontradas algumas parcelas com uma grande concentração de mudas de Pinus nos estratos B e C, deixando o índice alcançar o valor de 33. A média e o desvio-padrão dos Índices de Cox para os pinheiros nos estratos $\mathrm{B}+\mathrm{C}$ foram de $6,6 \pm 8,86$; considerando os pinheiros menores que $30 \mathrm{~cm}$ (estrato D) essas características alcançaram 4,9 $\pm 4,18$. A distribuição horizontal heterogênea, indicada pelos Índices de Cox, deve-se à variação do número de plantas que se encontrava entre zero e até mais de 100 por parcela. Semelhante à dependência encontrada para as latifoliadas (Figura 3), repetiu-se para os Pinus a relação positiva e significante (ao nível de $\mathrm{p} \leq 0,01$ ) entre o número de plantas por parcela e o Índice de Cox.

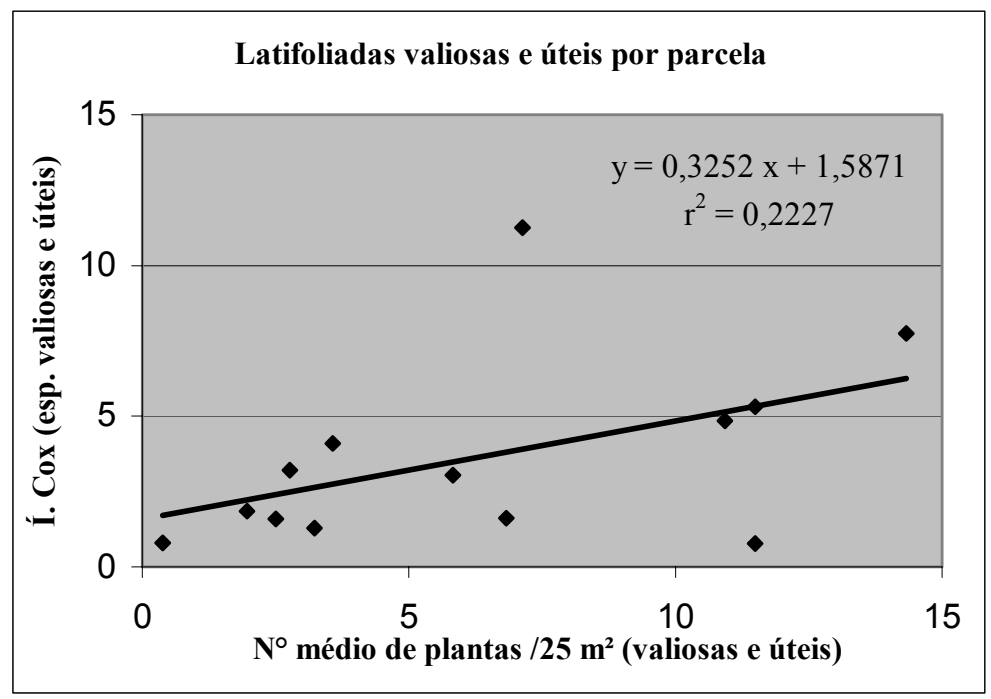

FIGURA 3: Relação entre o número de latifoliadas por parcela $\left(25 \mathrm{~m}^{2}\right)$ e o seu Índice de Cox

FIGURE 3: Relationship between the number of trees per plot (of $25 \mathrm{~m}^{2}$ ) and their Cox'Index.

A Tabela 6 permite comparar, para os estratos B e C diretamente, os Índices de Cox das latifoliadas e 
de Pinus (colunas 2 e 4). Nota-se que os padrões de dispersão num mesmo povoamento não se correspondem. Também não se correspondem esses padrões, quando se compara os Pinus sp. dos estratos B e C e os Pinus do estrato D. Conclui-se que, conforme o grupo de espécies, existiu num mesmo povoamento um padrão indeterminado de aglomeração horizontal dos indivíduos.

Juntando os dados das latifoliadas e dos Pinus, pode-se calcular um Índice de Cox para todo o sub-bosque com mais de $30 \mathrm{~cm}$ de altura. Os resultados são mostrados na coluna 6 da Tabela 8 . A média e o desvio-padrão do índice são de $5,1 \pm 5,48$. Ao comparar os índices dos povoamentos para os diferentes grupos de plantas, nota-se que os índices se complementam até certo grau. A conclusão disso é que a dispersão das plantas do sub-bosque fica mais uniforme, quando não se divide o total de plantas em grupos parciais. Pois para todo o sub-bosque junto não existiu a correlação entre o Índice de Cox e o número de indivíduos por parcela, relação essa que era significante quando separados os grupos das latifoliadas e dos Pinus.

\section{O Índice de Diversidade de Espécies (H’) de Shannon-Weaver}

Esse índice serve para quantificar a diversidade de espécies lenhosas do sub-bosque com uma altura de mais de $0,3 \mathrm{~cm}$. Esse índice aumenta com o número de espécies e, no caso em que dois povoamentos tenham o mesmo número de espécies, o índice será maior onde a proporção das espécies é mais uniforme. Influi também a área da amostra: quanto menor a área, menor o número de espécies, e menor o índice. O Índice de Shannon hoje provavelmente é o mais difundido para medir a diversidade, sendo freqüentemente usado também em estudos da vegetação nativa do Sul do Brasil (Nappo et al. 2000, Longhi et al. 2000, Nascimento et al. 2001).

Calcula-se um índice para cada povoamento $\left(\mathrm{H}_{\text {pov. }}\right)$, variando entre 1,3 e 3,5; foi encontrada uma correlação significante $\left(\mathrm{R}^{2}=0,591\right)$ entre o número de espécies $(n)$ e o índice $H^{\prime}$ do povoamento de seguinte forma: $\mathrm{H}_{\text {pov. }}^{\prime}=1,59+0,286 \cdot \mathrm{n}$

A existência de uma relação entre o índice H' e o número de espécies também foi salientado por Magurran (1988) e Gadow (1999).

Já que todas as parcelas tinham tamanho idêntico, justifica-se calcular também um índice para cada parcela $\left(\mathrm{H}^{\prime}\right.$ parc. $)$, sendo tais índices o resultado de uma amostragem aleatória, com distribuição normal (Magurran, 1988, p.36). O índice da parcela descreve a diversidade existente numa área de 5 por $5 \mathrm{~m}$. A variabilidade dos índices das parcelas de um povoamento é um indicador para a uniformidade da distribuição espacial da riqueza em espécies; e o coeficiente de variação (desvio-padrão relativo) então poderia ser usado como medida dessa uniformidade: quanto menor, mais uniforme se distribui a diversidade de espécies num povoamento.

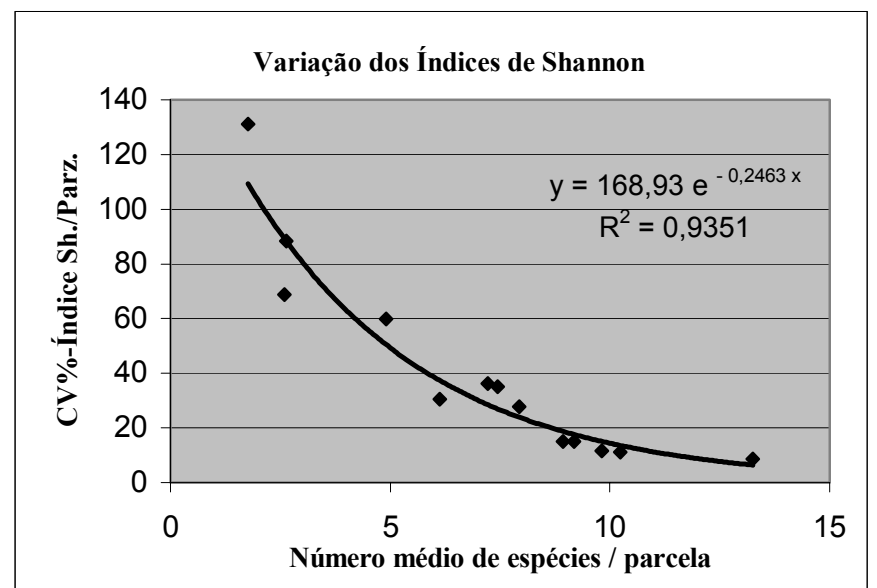

FIGURA 4: Número médio de espécies por parcela versus coeficiente de variação (CV\%) dos Índices de Shannon (H') das parcelas de um povoamento.

FIGURE 4: Mean number of species per sample plot and coefficient of variation (CV\%) of Shannon-Indices within stands. 
Dá para perceber que o coeficiente de variação aumenta, quando o número médio de espécies por parcela diminuiu (Figura 4). Mas também se observa, que a diversidade dentro de um povoamento diminui com o crescimento da média dos $\mathrm{H}_{\text {parc. }}$.

A distribuição mais uniforme dos $\mathrm{H}^{\prime}$ parc. foi observada no povoamento da Araucaria, a maior variação da diversidade em espécies de parcela em parcela foi registrada no povoamento $\mathrm{n}$. 5, que se originou de um renovação natural de Pinus.

Na maioria dos povoamentos (exceto o de n. 12, com os grandes grupos de Pinus no sub-bosque), encontrou-se uma relação recíproca entre os Índices de Shannon e de Cox. Isso significava que os povoamentos com altos Índices de Shannon (= sinal de riqueza em espécies) possuíam um Índice de Cox baixo, apontando para uma maior regularidade na distribuição das plantas do sub-bosque; e vice-versa, que

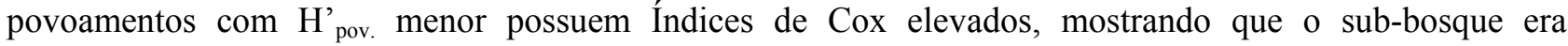
organizado em forma de manchas ou aglomerações.

Também foi analisado se o tamanho do povoamento tinha influência sobre a variabilidade dos índices $\mathrm{H}_{\text {par: }}$ : supunha-se, pois, que, quanto maior a área de um povoamento, maior a probabilidade de ocorrerem sítios diferentes com espécies próprias e diversidades menores dentro das parcelas. Mas não foi constatada relação alguma nesse sentido, o que foi atribuído ao fato de que as áreas dos povoamentos analisados não eram suficientemente extensas para apresentarem uma variabilidade maior de sítios.

Pode-se inferir, para a situação dos povoamentos em foco, que o conhecimento do número de espécies no sub-bosque já é um indício com respeito à sua distribuição: um número crescente de espécies significa um $\mathrm{H}_{\text {pov. }}$ maior e condiciona uma distribuição de indivíduos e espécies mais uniforme no povoamento.

\section{O Índice quantitativo de Sörensen $\left(C_{N}\right)$}

Com esse índice, mediu-se a semelhança do sub-bosque (estratos acima de 0,3 $\mathrm{m}$ ) dos povoamentos, comparando cada um com todos os outros, calculando segundo Magurran (1988, p.165):

$$
\mathrm{C}_{\mathrm{N}}=2_{\mathrm{jN}} /(\mathrm{aN}+\mathrm{bN})
$$

Em que: $\mathrm{aN}$ e $\mathrm{bN}=$ os números de indivíduos nos povoamentos a e $\mathrm{b}$, e $2_{\mathrm{jN}}=$ duas vezes a soma das freqüências de espécies em comum, contando-se de cada espécie o número de plantas daquele povoamento onde ela ocorre com menor freqüência.

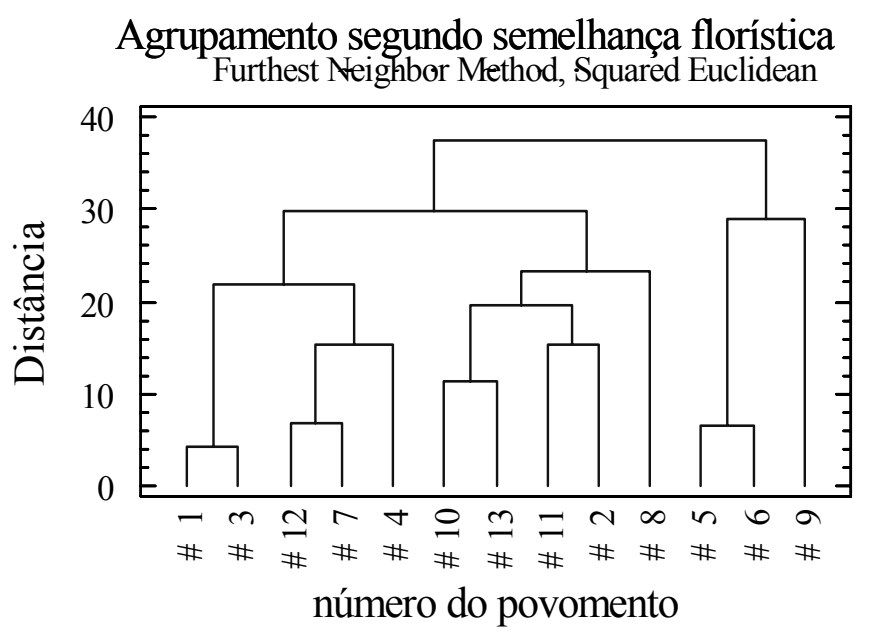

FIGURA 5: Dendrograma para a semelhança dos sub-bosques dos 13 povoamentos analisados, calculada com índices quantitativos de Sörensen.

FIGURE 5: Dendrogram showing similarity of substoreys of the 13 investigated stands, calculated using Sörensen's quantitative index of similarity.

Os índices $\mathrm{C}_{\mathrm{N}}$ assumem valores entre 0 e 1; quanto mais próximo de 1 , maior a semelhança de dois povoamentos. A menor semelhança, com índices $<0,10$, existiu entre o povoamento 5 (Pinus de renovação 
natural) e a maioria dos outros povoamentos; os índices de maior semelhança acusavam valores acima de 0,5 , e foram encontrados sobretudo para povoamentos de localização próxima, como os de n. 1, 3 e 7 e entre n. 5 e 6 . A proximidade faz com que exista uma maior probabilidade de espécies matrizes em comum. Também os povoamentos 10, 2 e 13 mostram, pelos índices, uma certa afinidade de sua composição, apesar de serem bem distantes um do outro; mas eles se situam relativamente próximos à restos da floresta nativa, $\mathrm{O}$ que poderia ajudar para explicar certas semelhanças de composição do sub-bosque. A Figura 5 ilustra essa proximidade florística por meio do agrupamento dos povoamentos por uma análise de cluster. Formam-se três clusteres maiores, definidas em parte pela proximidade geográfica, mas possivelmente também por outras características em comum, como pastoreio parcial, sinais de fogo, o uso da terra antes do reflorestamento e outras.

\section{CONCLUSÕES}

As capoeiras, que dominam a paisagem da região de estudo, compõem-se de uma vegetação monótona e pouco exigente. Por causa da degradação óbvia do sistema, causada pelo uso agrícola precedente, supõe-se que haja um desenvolvimento sucessional e um crescimento vegetativo bastante vagaroso. Estudando 12 povoamentos de Pinus $s p$., implantandos em sítios comprovadamente empobrecidos, verificou-se, porém, incrementos médios anuais surpreendentemente altos de até $50 \mathrm{~m}^{3}$ por hectare: um povoamento de Araucaria ainda produziu mais que $14 \mathrm{~m}^{3}$. Somente um povoamento tinha 10 anos de idade, os demais tinham de 25 a 30 anos. Reflorestar, em vez de abandonar áreas agrícolas, deveria ser portanto uma alternativa de produção a ser aconselhada pelos extensionistas. $O$ valor anual do incremento em madeira ultrapassava em várias vezes os rendimentos regionais das culturas agrícolas, como foram especificados por Basso e Garcia (1999).

Dentro dos plantios, estabeleceu-se um sub-bosque bastante diversificado quanto à sua distribuição horizontal e composição em espécies. Existem pesquisas de sub-bosques comparáveis, conduzidas em monoculturas de exóticas na Ásia e na África que também surpreenderam pela riqueza de espécies. Espécies de Pinus, pouco exigentes, possivelmente serviriam para iniciar os processos de diversificação florística de sítios degradados, acelerando o que ia ocorrer demoradamente em capoeiras durante os estágios iniciais da sucessão na região da Quarta Colônia. É óbvio que não se pode extrapolar os resultados do estudo presente para reflorestamentos de Pinus em geral; os povoamentos estudados, além de serem pequenos, estão cercados por vegetação de pousio e de cultivo agrícola. A proximidade de matrizes, sem dúvida, é pressuposto para a renovação espontânea de muitas espécies gaúchas (Coelho, 2000), o que deve dificultar o processo de renovação de nativas em plantações extensas. A área reduzida dos povoamentos estudados provavelmente também fez com que não tenham sido encontradas características de composição e diversificação diferentes entre parcelas localizadas mais perto da periferia ou do centro dos povoamentos.

Em mais do que $90 \%$ das 575 parcelas estudadas, encontraram-se representantes de ervas, gramas, cipós ou de samambaias; uma densidade elevada de plantas desse grupo influi negativamente sobre a probabilidade de estabelecimento de uma renovação natural dos próprios Pinus.

Foram encontradas ao total 121 espécies lenhosas no sub-bosque com uma altura superior a $0,3 \mathrm{~m}$, um número bastante elevado quando comparado com resultados de estudos semelhantes. Os povoamentos de maior diversidade chegaram a abrigar até mais de sessenta espécies, e foram poucas as parcelas que estavam sem exemplares de lenhosas, localizando-se a maioria das parcelas "vazias" no jovem povoamento número 5, denso por se originar de uma renovação natural de Pinus. A presença e a freqüência das espécies eram bem variadas: foram 25 espécies, por exemplo, das quais em todo o estudo se observou entre um e três indivíduos somente, e 34 das espécies foram encontradas em apenas uma dos 13 povoamentos analisados. Por outro lado, houve espécies que ocorreram em todos os povoamentos. Dentro das parcelas, encontrava-se em geral uma mistura de espécies, destacando-se, nesse sentido, o povoamento de Araucaria, possivelmente em conseqüência da sua posição num sítio relativamente favorável. Em síntese, tornou-se evidente que não seria suficiente só estudar um ou poucos povoamentos, ou levantar somente um pequeno número de parcelas para inventariar a composição florística do interior dos bosques de Pinus de uma região.

Entre as espécies do sub-bosque, foi registrada a ocorrência de árvores de valor e de utilidade. Quanto à sua ecologia, elas parecem ser representantes de estágios iniciais de sucessões. A ocorrência desses 
grupos de espécies em mais do que $70 \%$ das parcelas poderia tornar-se um desafio silvicultural, pois a maioria dos povoamentos estudados já tinha alcançado uma dimensão de corte final. Será que, após o aproveitamento dos Pinus, o sub-bosque poderia servir de ponto de partida para uma nova rotação, agora de uma floresta econômica, composta de nativas? A questão exige uma discussão ampla de pressupostos em termos de tratamentos pré-corte e de técnicas de corte. A variabilidade da composição do sub-bosque de povoamento em povoamento sobretudo dificulta a projeção da direção do desenvolvimento da sucessão iniciada abaixo dos pinheiros. A composição em espécies parece mais cunhada pelo histórico do sítio, o tratamento passado do povoamento e pela vegetação vizinha do que pelo fato de se encontrar numa monocultura de exóticas. Foi observada nos sub-bosques também a renovação natural do próprio Pinus, mas, surpreendentemente, houve maior ou igual número de parcelas com presença de camboatá, canela-guaicá, cestrum e pitangueira.

Os exemplares de Pinus no estrato com menos de $30 \mathrm{~cm}$ de altura se caracterizam por um aspecto encurvado e de crescimento até rastejante, o que certamente se deve a oferta reduzida de luminosidade próximo ao solo. Pode-se supor que tais plantas dificilmente prestam para serem transladadas para os povoamentos que seguem aos atuais. Observou-se que existia uma maior probabilidade de ocorrência de uma renovação dos Pinus no sub-bosque, quando a camada de liteira era menos espessa. Para dar início a um processo de renovação natural do Pinus, parece indicada a eliminação ou alteração de mantas homogêneas, fechadas e, sobretudo, espessas.

Em uma entre quatro parcelas, foram registradas 11 espécies de frutíferas (exóticas); a sua ocorrência no sub-bosque, especialmente perto de estradas, deixa supor que a sua propagação seja, na maioria dos casos antropogênica. Além dessas frutíferas, ocorrem outras 15 espécies nos sub-bosques que não são autóctones, ocorrendo árvores matrizes na região, plantadas para fins ornamentais ou para outro aproveitamento; exceto o pinheiro-brasileiro, Pinus e cinamomo, a maioria das plantas desse grupo somente foi encontrada em um único povoamento. Concluímos disso, que as exóticas com frutas comestíveis levam vantagem para sua disseminação na paisagem. Concluímos também que a povoação colonial uniforme na região, com jardins, pomares e plantios ornamentais provoca num lado uma certa adulteração da flora nativa, por outro, contribui para uma diversidade maior de estágios de renovação natural observada nos sub-bosques dos reflorestamentos.

Para quantificar a situação de renovação, foram calculadas várias medidas as quais ajudam elucidar alguns aspectos de diversidade do sistema.

O Índice de Cox foi escolhido para quantificar os padrões de distribuição espacial das plantas lenhosas dentro dos povoamentos; a disponibilidade de um grande número de amostras idênticas possibilitou a comparação direta dos índices calculados. Foi verificada uma correlação estreita entre o Índice de Cox e o número médio de plantas por parcela: quanto maior esse número, maior a formação de aglomerações ou de grupos dentro do povoamento. Quando ocorrem muitas espécies, aconselha-se calcular tal índice não para espécies individuais, mas, sim, para grupos destas ou para toda a população do sub-bosque de um povoamento: isso porque índices para caracterizar a dispersão de indivíduos de espécies singulares tendem a assumir valores extremos. Conforme a agregação de espécies escolhidas, encontrara-se neste estudo índices bem diferentes dentro de um mesmo povoamento, indicando que não existe um tipo de aglomeração ou dispersão só de plantas nos sub-bosques dos plantios de pinheiros. Para interpretar os resultados, tendo em vista o manejo do povoamento, escolheu-se um agrupamento de espécies conforme critérios de utilidade florestal e madeireiro; as grandezas desses índices deixam concluir que existem padrões de distribuição, desde ao acaso até fortemente aglomerado, mas não uniforme. A conclusão, para uma eventual transposição do achado para o manejo prático, é de evitar tratamentos sistemáticos, a favor da consideração da situação local, não somente de um povoamento inteiro, como também nas suas partes.

A própria renovação natural dos Pinus nos sub-bosque não foge dessa regra: apesar do estrato superior ser composto de muitas árvores matrizes potenciais, verificou-se um aparecimento fortemente aglomerado de jovens pinheiros.

Foi usado o Índice de Shannon para quantificar a diversidade de espécies, computado em dois níveis: uma vez como índice para o povoamento inteiro, e outra, como índice para cada uma das parcelas dentro do 
povoamento. Os índices dos povoamentos possuem uma correlação positiva com o número de espécies; eles alcançaram valores de até 3,4 - o que corresponde à grandeza dos índices publicados para os estratos arbóreos de florestas nativas sul-brasileiras. A análise dos índices por parcela individual serve para conhecer o padrão da distribuição horizontal dos índices de diversidade dentro de um povoamento. Verificou-se que, quanto maior o valor do índice de diversidade do povoamento, mais uniformemente distribuídos sobre a sua área se apresentam os índices das parcelas. Isso também significa para um povoamento, em que uma maior riqueza do seu sub-bosque em espécies é acompanhada de uma distribuição espacial mais uniforme da diversidade em espécies. O Índice de Shannon é relativamente sensível ao tamanho das amostras; por isso, os valores encontrados valem para parcelas de $25 \mathrm{~m}^{2}$, parcelas de outras áreas teriam índices diferentes. Quanto aos índices para os povoamentos inteiros, por terem áreas maiores, não existirá uma dependência assim.

Para medir a semelhança da composição dos povoamentos em espécies, foi usado o Índice modificado de Sörensen; vale a pena ponderar a ocorrência de espécies com a sua freqüência, porque os povoamentos tinham áreas diferentes. Os índices calculados para os sub-bosques mostraram um certo parentesco de espécies, quando os povoamentos se localizaram não muito distantes um do outro. Apesar de os povoamentos estudados ocorrerem numa região limitada, permaneceu muita individualidade na composição dos seus sub-bosques. Esse fato supostamente pode-se originar, entre outros, da composição específica da vegetação circundante, acompanhado dos efeitos do manejo que antecedeu o reflorestamento da área.

A comparação dos três índices usados, para os dados do sub-bosque de pinheiros, leva-nos à conclusão que cada um é capaz de caracterizar uma parte da estrutura complexa do interior dos povoamentos, complementando-se os seus valores informativos. Recomenda-se, por isto, usar vários índices quando, por exemplo, a intenção é de entender um sistema na busca de auxílio para decisões de tratamento e manejo. Também ficou claro que o sistema "sub-bosque de Pinus sp." não é algo suficientemente homogêneo para um trato sistemático e uniforme, mas, sim, com características locais a serem consideradas.

A análise desses povoamentos pequenos na paisagem colonial nos deixa concluir ainda que a monotonia desses capões somente é uma impressão superficial, enquanto o seu sub-bosque se caracteriza por uma elevada biodiversidade. O sistema, por isso, merecia atenção como ferramenta silvicultural para melhoria ecológica de sítios empobrecidos; a sua economicidade, por outro lado, servia de aliado para convencer proprietários e extensionistas aceitá-lo como um cultivo colonial alternativo.

\section{AGRADECIMENTOS}

Agradecemos ao professor Dr. Solon Jonas Longhi pela revisão da identificação botânica e a proposta para uma agregação qualitativa das espécies.

Os nossos agradecimento também ao Engenheiro Florestal, Mestre, Fabrício J. Sutili, pela revisão do texto presente.

Os trabalhos de campo fizeram parte do projeto "Revitalização da pequena propriedade rural na região central do Rio Grande do Sul, Brasil, pelo cultivo florestal” apoiado pela Academia Austríaca de Ciências e pelo Ministério de Relações Exteriores da Áustria.

\section{REFERÊNCIAS BIBLIOGRÁFICAS}

BASSO, N. ; GARCIA, D. Análise da agricultura do município de Ivorá - RS. Ijui : UNIJUÍ, Dep. de Estudos Agrários, 1999. 40p.

BELLINASO, S. Os heróis de Val de Búia. Ivora : Ed. Diác.S.Bellinaso, 2000. 160p.

BONE, R.; LAWRENCE, M. ; MAGOMBE, Z. The effect of Eucalyptus camaldulensis (Dehn) plantation on native woodland recovery on Ulumba Mountain, southern Malawi. For. Ecol. Manage., v. 99, p. 83-100, 1997.

BROCKERHOFF, E.G.; ECROYD, C.E.; LECKIE, A.C. ; KIMBERLEY, M. O. Diversity and succession of adventive and indigenous vascular understorey plants in Pinus radiata plantation forests in New Zealand. For. Ecol. Manage., v.185, p. 307-326, 2003.

COELHO, G.C. A floresta nativa do noroeste do RS : questões relevantes para conservação. Caderno de Pesquisa Sér. Bot., Santa Cruz do Sul, v.12, n.1, p. 17-44, 2000. 
COX, F. Dichtebestimmung und strukturanalyse von pflanzenpopulationen mit hilfe von abstandsmessungen. Mitt. BFA Forst- u. Holzwirtschaft Reinbeck, v. 87, p.1-161, 1971.

DUELLI, P. ; OBRIST, M.K. Biodiversity indicators: the coice of values and measures. Agric. Ecosyst. Environ., v. 98, p. 87-98, 2003.

ECKMÜLLNER, O. Einfluß der probeflächengröße auf maßzahlen der biodiversität. 11. Tagung der sektion forstliche biometrie und informatik des deutschen verbandes forstlicher forschungsanstalten. Tagungsband, p. 18-24, 1998.

FANG, W. ; . PENG, S.L Development of species diversity in the restoration process of establishing a tropical manmade forest ecosystem in China. For. Ecol. Manage., v. 99, p. 185-196, 1997.

GADOW , K. von Waldstruktur und Diversität. Allg. Forst- u. J.- Ztg. ,v. 170, p. 117-122, 1999.

GELDENHUYS, C.J. Native forest regeneration in pine and eucalypt plantations in Northern Province, South Africa. For. Ecol. Manage., v. 99, p. 101-116, 1997.

GUARIGUATA, M.R.; RHEINGANS R. ; MONTAGNINI, F. Early Woody Invasion Under Tree Plantations in Costa Rica: Implications for Forest Restoration. Restoration Ecology, v. 3, n.4, p. 252-260, 1995.

HAGGAR, J., WIGHTMAN, K. ; FISHER, R. The potential of plantations to foster woody regeneration within a deforested landscape in lowland Costa Rica. For. Ecol. Manage. , v. 99, p. 43-54, 1997.

HARRINGTON, R.A. ; EWEL, J. J. Invasibility of tree plantations by native and non-indigenous plant species in Hawaii. For. Ecol. Manage. , v. 99, p. 153-162, 1997.

HEALEY, S.P. ; GARA, R. I. The effect of a teak (Tectona grandis) plantation on the establishment of native species in an abandoned pasture in Costa Rica. For. Ecol. Manage. , v. 176, p. 497-507, 2003.

HUMMEL, S. Understory development in young Cordia alliodora plantations. New Forests, v. 19, p.159-170, 2001.

IVANAUSKAS, N.M.; RODRIGUES, R.R. ; NAVE, A, G. Fitosociologia de um trecho de Floresta Estacional Semidecidual em Itatinga, São Paulo, Brasil. Scientia Forestalis , v. 56, p. 83-99, dez. 1999.

JANNASCH, R. Karte der Kolonien im Staate Rio Grande do Sul. Berlin : Lith. Anst.v.Leopold Kraaty, 1898.

KEENAN, R.; LAMB, D.; WOLDRING, O.; IRVINE, T.; JENSEN, R. J. Restoration of plant diversity beneath tree plantations in Northern Australia. For.Ecol.Manage. , v. 99, p. 116-132, 1997.

LEITE, E.J. Spatial distribution patterns of riverine forest taxa in Brasília, Brazil. For. Ecol. Manage. , v. 140 , p. $257-$ $264,2001$.

LONGHI, S.J.; ARAUJO, M.M.; KELlinG, M.B; HOPPE, J.M.; MÜlleR, I; BORSOI, G.A. Aspectos fitossociológicos de fragmento de floresta estacional decidual, Santa Maria, RS. Ciência Florestal , v.10, n.2, p. 59-74, 2000 .

LOUMETTE, J.J; CHUTTEL, C. Understory vegetation in fast-growing tree plantations on savanna soils in Congo. For. Ecol. Manage. , v. 99, p. 65-82, 1997.

LUGO, A.E. The apparent paradox of reestablishing species richness on degraded lands with monocultures. For. Ecol. Manage. , v. 99, p. 9-20, 1997.

MAGURRAN, A.E. Ecological diversity and its measurement. Princeton : Princeton Univertity Press, 1988.179 p.

MINSSEN, E. Comunicação pessoal : “em 13 de maio de 1897, 57 colonos reunidos em Maratá (Zona Colonial Alemã) criaram a Sociedade Livre de Sylvicultura. Dentre as obrigações ....de plantarem no mínimo 200 araucarias por ano........ “. S.L. : s.n., 2001. E-mail de 30 de março de 2001.

NASCIMENTO, A.R.T.; LONGHI, S.J. ; BRENA, D.A. Estrutura e padrões de distribuição espacial de espécies arbóreas em uma amostra de florests ombrófila mista em Nova Prata, RS. Ciência Florestal , v. 11, n.1, p. 105-119, 2001 .

NAPPO, M.E.; OLIVEIRA F ${ }^{\circ}$, A.T.de ; MARTINS, S. V. A estrutura do sub-bosque de povoamentos homogêneos de Mimosa scabrella Bentham, em área minerada, em Poços de Caldas, MG. Ciências Florestal, v. 10, n.2, p. 17-29, 2000 .

NEBEL, G.;DRAGSTED, J. ; VANCLAY , J. K. Structure and floristic composition of flood plain forests in the Peruvian Amazon. II: The understorey of restinga forests. For. Ecol. Manage. , v.150, p. 59-77, 2001.

NEBEL, G.; KVIST ,L.P.; VANCLAY ,J.K.; CHRISTENSEN, H.; FREITAS, L. ; RUIZ, J. Structure and floristic 
composition of flood plain forests in the Peruvian Amazon. I: Overstorey. For. Ecol. Manage. ,v.150, p. 27-57, 2001.

OBERHAUSER, U. Secondary forest regeneration beneath pine (Pinus kesiya) plantations in the northern Thai highlands: a chronosequence study. For.Ecol.Manage., v. 99, p. 1171-183, 1997.

PALUMBO, R. Holzmesskundliche Untersuchung des Hauptbestandes und Analyse der Naturverjüngung unter Aufforstungen mit Pinus elliottii, Pinus taeda und Araucaria angustifolia in Rio Grande do Sul (Südbrasilien). Wien : Diplomarbeit, Universität für Bodenkultur, Wien, 1999. $113 \mathrm{p}$

PARROTTA, J.A.; KNOWLES, O.H. ; WUNDERLE Jr., J. M. The effect of overstory composition on understory woody regeneration and species richness in 7-year-old plantations in Costa Rica. For. Ecol. Manage. , v. 99, p. 21-42, 1997.

SAHA ,S. Vegetation composition and structure of Tectona grandis (teak, family Verbenaceae) plantations and dry deciduous forests in central India. For. Ecol. Manage., v. 148, p. 159-168, 2001.

SCHEUBER M. Inventur und Monitoring von Galeriewäldern in Zentralbrasilien. 1998. Dissertation - AlbertLudwigs-Universität Freiburg i. Br., 1998.

STOCKWELL, D.R.B. ; PETERSON, A. T. Effect of sample size on accuracy of species distribution models. Ecological Modelling, v. 148, p. 1-13, 2002.

VRIES, P.G.de Sampling Theory for Forest Inventory. Berlin : Springer Verlag , 1986. 399 p.

YIRDAW E. Diversity od naturally-regenerated native woody species in forest plantations in the Ethiopian highlands. New Forests , v. 22, p.159-177, 2001.

ZELL, J. Assumptos florestaes : problemas para o Governo do Estado do Rio Grande do Sul. Porto Alegre : Typographia do Centro, 1929. 28 p. Memorial dirigido respeitosamente ao Senhor Dr.Getúlio Dornelles Vargas. DD.Presidente do estado 